This item was submitted to Loughborough's Research Repository by the author.

Items in Figshare are protected by copyright, with all rights reserved, unless otherwise indicated.

\title{
Car seat design to improve rear-impact protection
}

PLEASE CITE THE PUBLISHED VERSION

http://dx.doi.org/10.1177/2041299110393188

PUBLISHER

SAGE (@ the authors)

VERSION

AM (Accepted Manuscript)

LICENCE

CC BY-NC-ND 4.0

REPOSITORY RECORD

Himmetoglu, Selcuk, Memis Acar, Kaddour Bouazza-Marouf, and Andrew J. Taylor. 2019. "Car Seat Design to Improve Rear-impact Protection". figshare. https://hdl.handle.net/2134/15524. 
This item was submitted to Loughborough's Institutional Repository (https://dspace.lboro.ac.uk/) by the author and is made available under the following Creative Commons Licence conditions.

\section{creative
commons}

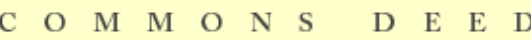

Attribution-NonCommercial-NoDerivs 2.5

You are free:

- to copy, distribute, display, and perform the work

Under the following conditions:

Attribution. You must attribute the work in the manner specified b the author or licensor.

Noncommercial. You may not use this work for commercial purposes.

No Derivative Works. You may not alter, transform, or build upon this work.

- For any reuse or distribution, you must make clear to others the license terms of this work.

- Any of these conditions can be waived if you get permission from the copyright holder.

Your fair use and other rights are in no way affected by the above.

This is a human-readable summary of the Leqal Code (the full license).

\section{Disclaimer 만}

For the full text of this licence, please go to: http://creativecommons.org/licenses/by-nc-nd/2.5/ 


\title{
Car seat design to improve rear-impact protection
}

\author{
S Himmetoglu' ${ }^{1 *}$ M Acar ${ }^{2}, \mathrm{~K}$ Bouazza-Marouf ${ }^{2}$, and A J Taylor $^{2}$ \\ ${ }^{1}$ Mechanical Engineering Department, Hacettepe University, Ankara, Turkey \\ ${ }^{2}$ Wolfson School of Mechanical and Manufacturing Engineering, Loughborough University, UK
}

\begin{abstract}
This study presents car seat concepts which are designed to mitigate whiplash injuries through coordinated motion of seat components for a wide range of crash severities. In order to evaluate the effectiveness of the proposed car seat concepts, computational multibody models of a generic car seat and a biofidelic 50th-percentile male human model for rear impact are developed. A number of car seat concepts are shown to reduce the risk of whiplash injuries by utilizing head restraint support and energy-absorbing features, which remain reusable after impact.
\end{abstract}

Keywords: car seat design, whiplash, rear impact, energy absorption, human body model

\section{INTRODUCTION}

Whiplash injuries (disorders) are a common consequence of road traffic accidents and they are caused by the sudden differential movement between the head and torso. Whiplash injuries, or 'whiplash', can result from impacts in all directions but the highest risk of sustaining whiplash occurs in rear-end collisions [1,2]. Whiplash is defined as a minor neck injury; however, it can still lead to long-term disablement and discomfort in the neck, and is associated with substantial socio-economical cost, estimated to be around $£ 2.5$ billion in the UK [3] and $\$ 8.2$ billion in the USA [4] annually.

A head restraint with good stiffness and energyabsorbing characteristics, positioned at the right height and with an appropriate (small) back-set distance, can help to reduce whiplash risks in rearend collisions. However, during a rear impact, the head restraint and the seat must work together in order for the seat to absorb the crash energy effectively.

A car seat may perform well when it is tested using a single crash pulse. However, in real-world crashes, a car seat may be subjected to a variety of crash pulses and may comparatively underperform in some conditions. This problem is indicated by realworld accident data analyses in which insurance claims and medical reports are utilized to classify the severities of whiplash injuries reported by the victims [2, 5]. The latest whiplash tests of the European New Car Assessment Programme (EuroNCAP) [6] also showed that a considerable number of seats did not provide optimum protection when subjected to the low-, high-, and medium-severity crash pulses. Therefore, a judicious selection of a crash pulse range is needed for rear-impact whiplash assessment and seat design.

Road traffic accident data show that single rearimpacts with almost full overlap (50-100 per cent), represent the most common rear-impact configuration in which whiplash injuries occur [1, 7]. Comprehensive data representing European rearend collisions between 1996 and 2004 indicate that in single rear-impacts, 77 per cent of the cars received a $\Delta \mathrm{V}$ lower than $15 \mathrm{~km} / \mathrm{h}, 16$ per cent received a $\Delta \mathrm{V}$ between 15 and $25 \mathrm{~km} / \mathrm{h}$, and 7 per cent received a $\Delta \mathrm{V}$ higher than $25 \mathrm{~km} / \mathrm{h}$ [1]. (In accident analysis, the term $\Delta \mathrm{V}$ is typically used to classify crash severity, and it is defined as the area under the acceleration-time curve of the struck vehicle over the course of the impact.) In the same study, the front-seat occupants who were involved in single rear-impacts and also suffered from whiplash injuries, were further analysed. The results showed that 35 per cent of the injured occupants received a 
$\Delta \mathrm{V}$ lower than $9 \mathrm{~km} / \mathrm{h}, 55$ per cent experienced a $\Delta \mathrm{V}$ between 9 and $20 \mathrm{~km} / \mathrm{h}$, and 10 per cent received a $\Delta \mathrm{V}$ higher than $20 \mathrm{~km} / \mathrm{h}$.

For crash severities greater than a $\Delta \mathrm{V}$ of $25 \mathrm{~km} / \mathrm{h}$, the rate of occurrence of rear-end collisions is much lower. However, at such relatively high $\Delta \mathrm{V}$ levels, injuries which are different and/or more severe than whiplash become dominant. Such injuries were found at the head, thorax, spine, and upper/lower extremities, and included contusions, concussions, and fractures of the upper extremity and spine $[1,7-10]$.

Considering the recent road-traffic accident data, a $\Delta \mathrm{V}$ range between 5 and $30 \mathrm{~km} / \mathrm{h}$ should be considered for whiplash risk assessment in antiwhiplash car seat design since it can account for a wide rear-impact severity range where whiplash injuries are common. This $\Delta \mathrm{V}$ range covers the $\Delta \mathrm{V}$ levels $(9-20 \mathrm{~km} / \mathrm{h})$ where whiplash risk is high and also includes the $\Delta \mathrm{V}$ levels $(13-27 \mathrm{~km} / \mathrm{h})$ where longterm (over one month) whiplash risk is significant $[1,11,12]$.

This study presents reactive car seat concepts which can absorb the crash energy effectively and mitigate whiplash injuries optimally for crash severities ranging from 5 to $30 \mathrm{~km} / \mathrm{h}$ of $\Delta \mathrm{V}$ while remaining reusable after impact. The proposed car seat concepts are developed using a relatively simple multibody human model which was shown to be biofidelic [13]. The cervical spine of the human model was separately developed and verified for rear impact, prior to its integration with the human model [14].

\section{ANTI-WHIPLASH SEAT DESIGNS IN THE MARKET}

A well-designed car seat should reduce occupant acceleration, support the head effectively, reduce ramping, and limit seat-back rebound so that minimum neck internal motion and low neck forces are ensured throughout the impact. Ramping is a typical consequence of rear impacts and it can be defined briefly as the upward motion of the upper torso along the seat-back. Ramping occurs as a combination of two main effects: first, the upper and lower spines (i.e. thoracic and lumbar spines) extend backwards against the seat-back during the early stages of a typical rear impact as the occupant is loaded by the seat-back; hence the first thoracic vertebra (T1) (or the upper torso) moves upwards and backwards relative to the seat-back. This phenomenon is called spine straightening (or spine elongation), during which the neck is pushed up and compressed. The second effect arises from the fact that in a typical car seat, the front and the rear seat-backs are inclined backwards from the vertical (typically between $20^{\circ}$ and $30^{\circ}$, see Fig. 1). In addition, when a rear impact occurs, the front seat-backs rotate backwards as they are loaded by the occupants. Therefore, the initial inclination and/or backward rotation of the seat-back cause the occupant to slide upward along the seatback. Ramping can lower the position of the head restraint with respect to the head and even lead to the ejection of the occupant at severe rear impacts.

A comprehensive literature survey by Himmetoglu [15] indicated that for effective whiplash mitigation, making structural and geometrical improvements on the car seat offers greater potential than modifying solely the properties of seat-back foam-and-suspension $[16,17]$. For a given initial posture of the occupant, modifying the mechanical properties of the recliner and improving head restraint geometry (i.e. height and back-set) have been found to be the most influential techniques to reduce whiplash injuries $[15,16]$.

A considerable number of seat and head restraint designs exist in the literature for whiplash mitigation. However, in principle, all of these designs can be classified into two main groups. In the first group, the emphasis is on absorbing the crash energy by controlled motion of the seat, hence reducing occupant acceleration. The most prominent and successful design on the market is the Volvo Whiplash Protection System (WHIPS), in which there is a plastically deformable, sacrificial link in the recliner mechanism which allows the seat-back to

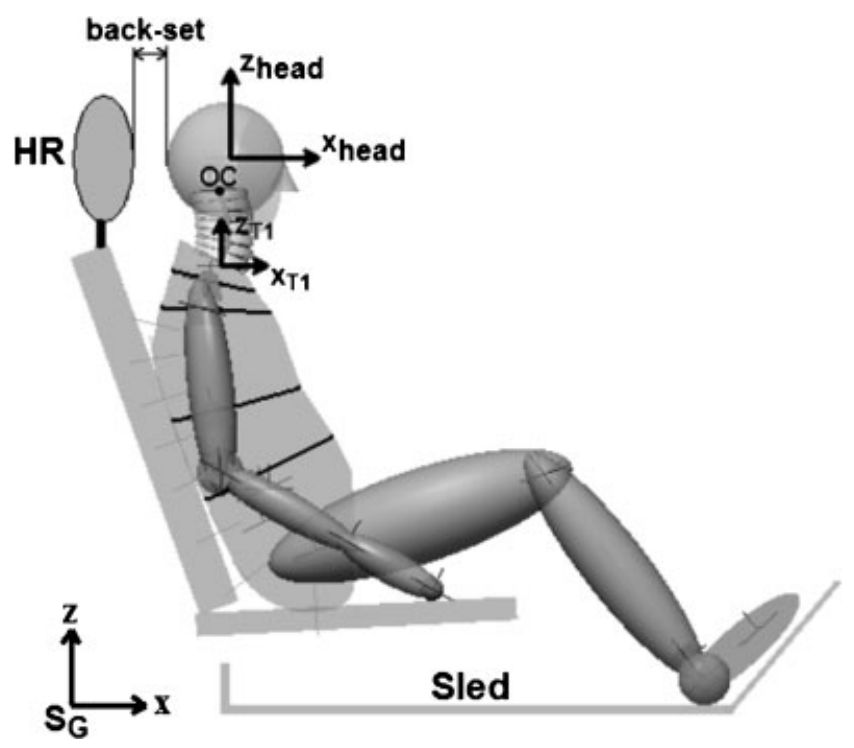

Fig. 1 The seat-occupant system 
recline so as to absorb energy in a controlled manner $[18,19]$. Thus, the mechanism will need to be replaced after the impact.

The second group comprises active head restraint designs (reactive or pro-active) in which the emphasis is on providing early head support by automatically positioning the head restraint close to the head during the early stages of the rear impact. There are many variants of this design in the market and the most prominent one is the Saab Active Head Restraint (SAHR) [20].

SAHR and WHIPS have consistently earned the highest dynamic seat ratings in the International Insurance Whiplash Prevention Group (IIWPG) and EuroNCAP whiplash tests [2]. An analysis of realworld accident data by Kullgren et al. [21] indicated that SAHR and WHIPS, along with some other similar systems, have 50 per cent lower risk of long-term whiplash symptoms in comparison with the typical car seats introduced after 1997. Kullgren et al. [21] also found a correlation between dynamic seat ratings and real-world whiplash injury outcome. The latest EuroNCAP whiplash test results show that the majority of the seats from 2008 and 2009 model year cars needed further improvement, including some with active head restraints [6]. The results indicated that many seats did not optimally respond to the three crash pulses (low, medium, and high severity) applied in the EuroNCAP whiplash test procedure. Only 29 per cent of the seats earned good ratings, whereas the remaining 50 per cent and 21 per cent received marginal and poor ratings, respectively. This indicates that 29 per cent of the seats have comparatively lower risk of whiplash injury than the seats rated as marginal and poor.

Following the introduction of SAHR and WHIPS about a decade ago, a considerable number of antiwhiplash seat designs have been proposed. However, to the best of our knowledge, the performances of these designs have not been investigated in the literature for a representative range of crash severity. In the only comprehensive work by Viano [20], the effectiveness of SAHR was shown by conducting rear-impact tests using the Hybrid III dummy (with and without the RID-neck) at a crash severity range between 7 and $35 \mathrm{~km} / \mathrm{h}$ of $\Delta \mathrm{V}$, although a few other tests were also conducted at higher severity levels.

In a previous study by Himmetoglu et al. [22], a number of energy-absorbing seat concepts, without a head restraint, were reported. The objective was to determine the most effective seat design parameters in order to align the head and neck with the upper torso and ensure minimum neck internal motion.
The results showed the benefits of energy-absorbing seats.

\section{A SEAT-OCCUPANT SYSTEM FOR REAR-IMPACT SIMULATION}

Human body models are indispensable tools to develop car seat models and other safety systems for a wide range of occupant population and real-world accident conditions. Current mechanical dummies have very limited capability to reproduce the effects of the active musculature present in the human body. Human volunteers can only be tested at low severities for the safety of subjects. Cadavers usually represent older subjects; they have no muscular tone and reflexes, and, in addition, the mechanical properties of soft tissues change after death. It has been found that active muscle (i.e. muscle tensing or contracting) effects must be taken into consideration in order to simulate human impact response accurately in realworld accidents [23-25]. For these reasons, computational modelling offers an effective and economical way to simulate human impact response, which is controlled by complex neural feedback mechanisms involving voluntary and reflex muscle contractions. Computational modelling is now emerging as a tool to evaluate the performance of safety systems in regulatory and consumer testing [26]. Therefore, in this study, a human model with improved biofidelity is used to develop whiplash-mitigating reactive car seat concepts as described below.

A biofidelic 50th-percentile male lumped-parameter multibody human model, as shown in Fig. 1, was developed by Himmetoglu et al. [13, 14, 22] using MSC VisualNastran 4D with Matlab-Simulink and validated using the responses of seven healthy 50th-percentile male volunteers from the Japan Automobile Research Institute (JARI) sled tests [27]. These tests were performed at an impact speed of $8 \mathrm{~km} / \mathrm{h}$ with a rigid seat (i.e. a seat having all rigid surfaces and a fixed recliner), and without head restraint and seat-belt. The volunteers were relaxed and unaware of the timing of the impact. The human model was rigorously validated so that it would behave like an average volunteer in the JARI sled tests when subjected to the same rear-impact conditions. In these tests, the head was allowed to extend due to the absence of head restraint, hence the mechanical properties of the joints were validated for a larger range of joint rotations [13].

The lumped-parameter human model is composed of rigid bodies connected by rotational springs and dampers. The model does not incorporate 
individual modelling of the soft tissues, such as the muscles; however, the stiffness and time-dependent damping characteristics of the joints, which constitute the novelty of this model, help to represent muscle tensing behaviour and the increase in the resistance of the human body under dynamic conditions. For crash severities around the validation point (i.e. JARI sled test severity), the human model was shown to have improved biofidelity in comparison with the BioRID, which is the most biofidelic rearimpact dummy to date [13]. In modelling the joint range-of-motions to simulate severe cases, the static torque values of the joint stiffness functions were increased steeply in agreement with those of the mechanical and computational models of the BioRID. The developed human model helps to economically and more accurately simulate different rear-impact scenarios and facilitate 'what-if' tests. It successfully satisfies the rear-impact dummy biofidelity evaluation criteria [28] based on the head and upper torso responses of the JARI volunteers.

A generic multibody car seat model was also developed to implement various anti-whiplash devices (AWDs), seat-back, head restraint, and recliner properties. In validating the human model, the rigid seat used in the JARI sled tests was modelled first and a contact model was developed to simulate the interaction of the human body segments with the rigid seat surfaces [13]. A typical head restraint (HR), attached to the seat-back as shown in Fig. 1, is included in the seat-occupant system model.

\section{REACTIVE CAR SEAT CONCEPTS}

Using the same driving posture as in the JARI sled tests and the rigid seat model as the basic configuration, several reactive car seat concepts are developed for whiplash mitigation. These car seat concepts incorporate AWDs which control effec- tively the relative motion between the structural members of the seat with the aim of providing optimum whiplash mitigation for a wide range of crash severities. The AWDs are passive devices consisting of non-linear spring-and-damper units. Using these AWDs, a typical car seat can be transformed into a seat which can offer improved protection in rear impacts. The AWDs become operational only when the corresponding breakaway forces and/or torques are exceeded. The crash energy is absorbed by these devices in such a way that optimum protection is provided at different crash severities. The required characteristics of the AWDs are determined using a wide range of $\Delta \mathrm{V}$ (between 4.5 and $35 \mathrm{~km} / \mathrm{h}$ ) and variety of crash pulses as presented in the references [2, 20, 29, 30].

Figure 2 shows schematic drawings of the reactive car seat concepts (denoted WMS and IFWMS) and a simplified model of a typical car seat (denoted TYPS). WMS and IFWMS are the modified versions of TYPS. Head restraint (denoted HR), seat-back (denoted SB), and seat-pan (denoted SP) are the main components of all the seats. The dimensions and masses of the individual seat components are the same for all the seats, and they are representative of the typical car seats in the market [31].

\subsection{Foam-plate concept}

It is costly to experimentally determine and numerically simulate the mechanical properties (such as foam and frame stiffness) of actual car seat components for a wide range of impact speeds. In the multibody model of each car seat concept shown in Fig. 2, the seat-back (SB) consists of a rigid plate (termed 'foam-plate') and a seat-back structure, which are of the same size as the seat-back. The foam-plate mimics the function of a typical seatback foam-and-suspension, and it is coupled to the
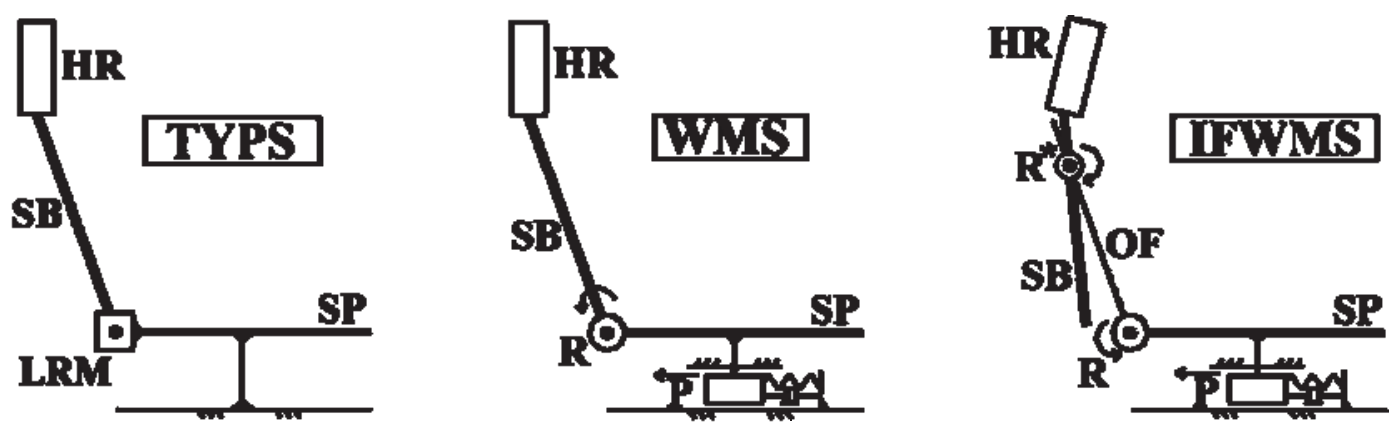

Fig. 2 Schematic drawings of the car seat concepts. HR: head restraint; SB: seat-back; SP: seatpan; LRM: locked recliner mechanism; OF: outer seat-back frame; $\mathrm{R}$ and $\mathrm{R}^{*}$ : rotational AWD; P: translational AWD 
seat-back structure by a translational spring-anddamper unit denoted by $\mathrm{P}^{*}$, as shown in Fig. 3(a). The foam-plate is in direct contact with the torso, thus there is distributed loading between the human model and the foam-plate. During impact, the foamplate allows the torso to penetrate into the seat-back structure by approximately $3 \mathrm{~cm}$ in addition to the static deformation caused by the occupant weight. Thus, the foam-plate can help to reduce back-set (see Fig. 1) in the early stages of the rear impact. The foam-plate enables all parts of the torso to penetrate into the seat-back structure by the same amount while preserving the posture of the spine that the occupant has before the impact. The foam-plate is integrated into the seat-backs of all three car seat concepts, which are the transformed versions of the JARI rigid seat used in the validation of the human model. Therefore, the feasibility of car seat concepts and their whiplash mitigation features can be economically investigated and compared using the successfully validated seat-occupant system as described in section 3 .

Figure 3(b) shows the stiffness and damping characteristics of the translational spring-and-damper unit $\mathrm{P}^{*}$ which are derived by analysing the differ-
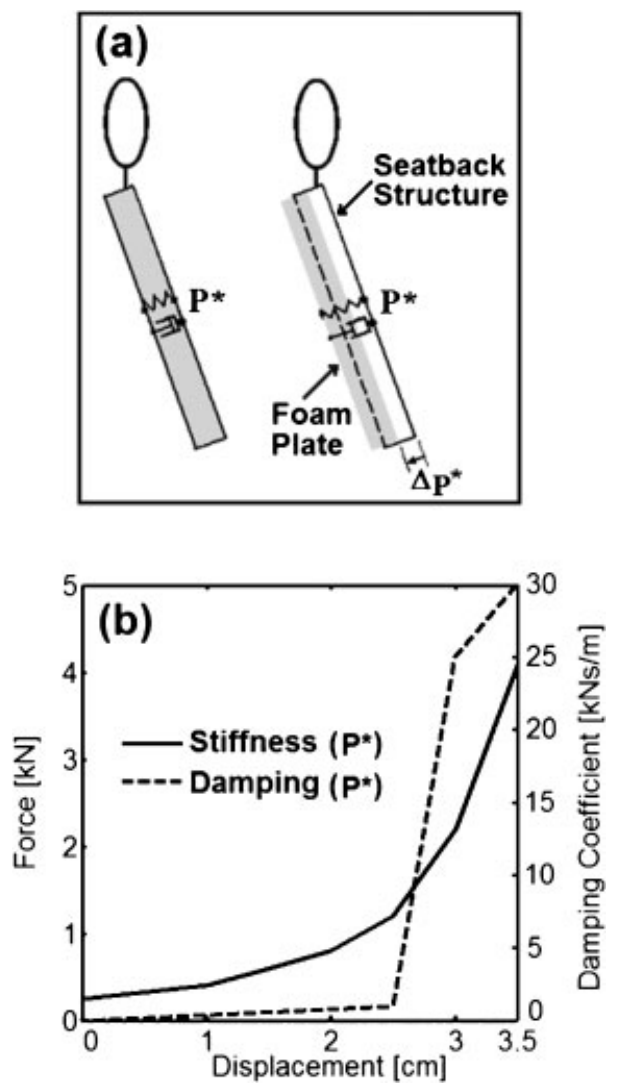

Fig. 3 Schematic illustration of the foam-plate, and its stiffness and damping characteristics ences in the responses of volunteers who were subjected to the JARI sled tests using both a rigid and a typical seat [27]. The stiffness characteristics of $\mathrm{P} *$ do not involve any breakaway force and the mass of the foam-plate is taken as $1 \mathrm{~kg}$. The displacement of the foam-plate is denoted by $\Delta_{\mathrm{P} *}$. Figure $3(\mathrm{~b})$ indicates that when a rear impact occurs, $\mathrm{P}^{*}$ applies lower levels of resistance to the motion of the foamplate in the first $2.5 \mathrm{~cm}$ of displacement; in a typical car seat this is equivalent to the sinking of the torso into the seat-back structure (or frame) during which seat-back foam-and-suspension are rapidly compressed. $\mathrm{P}^{*}$ applies high resistance to the motion of the foam-plate for displacements greater than $2.5 \mathrm{~cm}$, hence the foam-plate eventually bottoms out and the torso stops sinking into the seat-back structure. Similarly, in a typical car seat, when the torso eventually contacts the seat-back frame, it practically cannot compress the foam and suspension anymore.

In the rebound phase of a typical rear impact, the torso bounces from the seat-back frame and then seat-back foam-and-suspension become the only components that act directly on the torso. In order to simulate the rebound-motion characteristics in a practical and simple manner, a damping coefficient of $2 \mathrm{kNs} / \mathrm{m}$ is applied by $\mathrm{P}^{*}$ for the rebound (reverse) motion of the foam-plate.

\subsection{Mechanical properties of the typical car seat models (TYPS)}

The typical car seat model TYPS consists of a head restraint (HR), a seat-back (SB), and a seat-pan (SP). The recliner mechanism which connects the $\mathrm{SB}$ to the SP, remains locked during normal daily use, hence it is named 'locked recliner mechanism' and denoted by LRM, as shown in Fig. 2. When a rear impact occurs, the structure of the LRM deforms, and this causes the SB to rotate and horizontally translate with respect to the SP.

The mechanical properties of the LRM of TYPS are derived from the work of Eriksson [32] in which the validations of a number of typical car seat models were performed by subjecting typical car seats produced between the $1980 \mathrm{~s}$ and the mid-1990s [33] to rear-impact sled tests using two crash pulses with the same $\Delta \mathrm{V}$ but with different acceleration profiles. The information provided by Eriksson [32] is the only data-set available for modelling the mechanical properties of LRM using the multibody modelling approach. From this study, two typical car seat models, namely TYPS-B1 and TYPS-G2 are 
selected. Eriksson [32] indicated that TYPS-B1 had a higher whiplash risk than TYPS-G2. For both seats, Figs 4(a) and 4(b) present the stiffness characteristics for the rotational and translational (horizontal) deformations at the LRM respectively. The rotational damping characteristics of the LRM are given in Fig. 4(c), whereas the translational (horizontal) damping characteristics are modelled using constant damping coefficients of 10 and $6 \mathrm{kN} \mathrm{s} / \mathrm{m}$ for TYPS-B1 and TYPS-G2 respectively. In the stiffness characteristics of the LRM, as shown in Figs 4(a) and 4(b), the load increases in proportion to the deformation until the peak torque or force value is reached. For further deformations, there is a drop in torque or force. This is associated with the failure of the structure of the recliner mechanism (i.e. plastic deformation).

\subsection{Mechanical properties of the reactive car seat concepts (WMS and IFWMS)}

In WMS, the rotational AWD denoted by $\mathrm{R}$ is situated at the recliner and it replaces the LRM of TYPS. Thus, $\mathrm{R}$ functions as the recliner of WMS, and it enables the seat-back (SB) to rotate with respect to the seat-pan (SP). The translational AWD denoted by $\mathrm{P}$ is situated under the seat-pan and it permits the whole seat to translate backwards during rear impact.

The difference between IFWMS and WMS is that in IFWMS, the seat-back (i.e. the SB which the torso directly interacts with) functions as an inner frame which is pivoted to the outer seat-back frame (OF) by another rotational AWD denoted by $R^{*}$. In IFWMS, the outer seat-back frame (OF) is connected to the seat-pan (SP) by the rotational AWD R. When the breakaway torque at $\mathrm{R}^{*}$ is overcome due to the pressure applied by the torso on the seat-back (SB), a rotation at $\mathrm{R}^{*}$ occurs which is in the opposite direction to the rotation at $\mathrm{R}$. The abbreviations used in describing the car seat concepts are also listed in the Notation (Appendix).

Two different versions of WMS have been developed. WMS-ST has a stronger recliner (R), whereas WMS-SO has a softer one as shown by the stiffness characteristics of the rotational AWD R, given in Fig. 5(a). The recliner (R) of IFWMS is softer than that of WMS-SO on the whole. The recliners of WMSST, WMS-SO, and IFWMS have breakaway torques of $1.1 \mathrm{kNm}, 1 \mathrm{kNm}$, and $1 \mathrm{kNm}$ respectively.

For rearward rotation at $\mathrm{R}$, a constant damping coefficient of $1 \mathrm{Nms} / \mathrm{deg}$ is used for all three reactive car seat concepts. This is an estimation of the rotational damping coefficient for the deformation of the LRM in typical car seats [32]. For all the reactive car seat concepts, the rotational AWD R applies high damping ( $15 \mathrm{Nms} / \mathrm{deg})$ when the SB (in WMS seats) and OF (in IFWMS) start rotating forward (rebound motion), hence limiting rebound.

Figure 5(b) shows the stiffness and damping characteristics of the rotational AWD R* which has a breakaway torque of $1.35 \mathrm{kNm}$. A damping coefficient of $0.1 \mathrm{Nms} / \mathrm{deg}$ is applied by $\mathrm{R}^{*}$ in the reverse (rebound) motion.

The stiffness and damping characteristics of the translational AWD P, as shown in Fig. 5(c), are the same for all the reactive car seat concepts; the only difference is that the breakaway forces are $5 \mathrm{kN}$, $4.5 \mathrm{kN}$, and $4.25 \mathrm{kN}$ for WMS-ST, WMS-SO, and IFWMS respectively. For the backward motion of the seat-pan (SP), the damping function indicated by the dashed line in Fig. 5(c) is applied. On the other hand, for the rebound (forward) motion, $\mathrm{P}$ applies high damping $(30 \mathrm{kNs} / \mathrm{m})$ to ensure slow rebound of the seat-pan in order to minimize the risk of lowerextremity injuries. Otherwise, the lower extremities could possibly be compressed forcefully against the interior components (such as the steering wheel) of
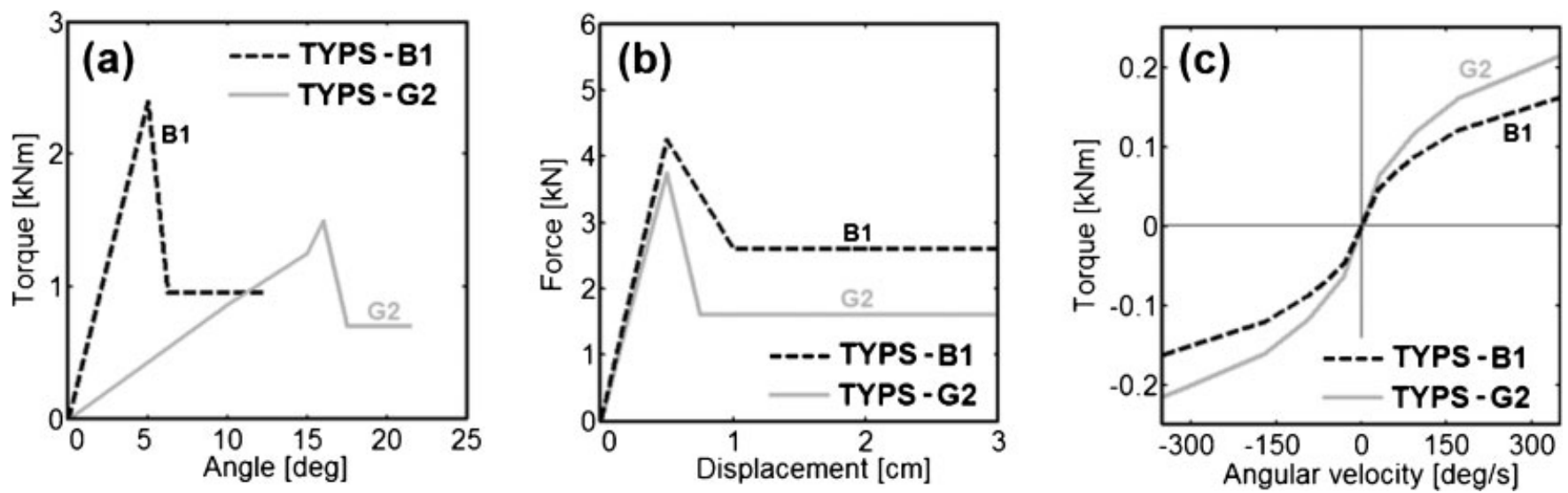

Fig. 4 The mechanical properties of the locked recliner mechanism (LRM) 

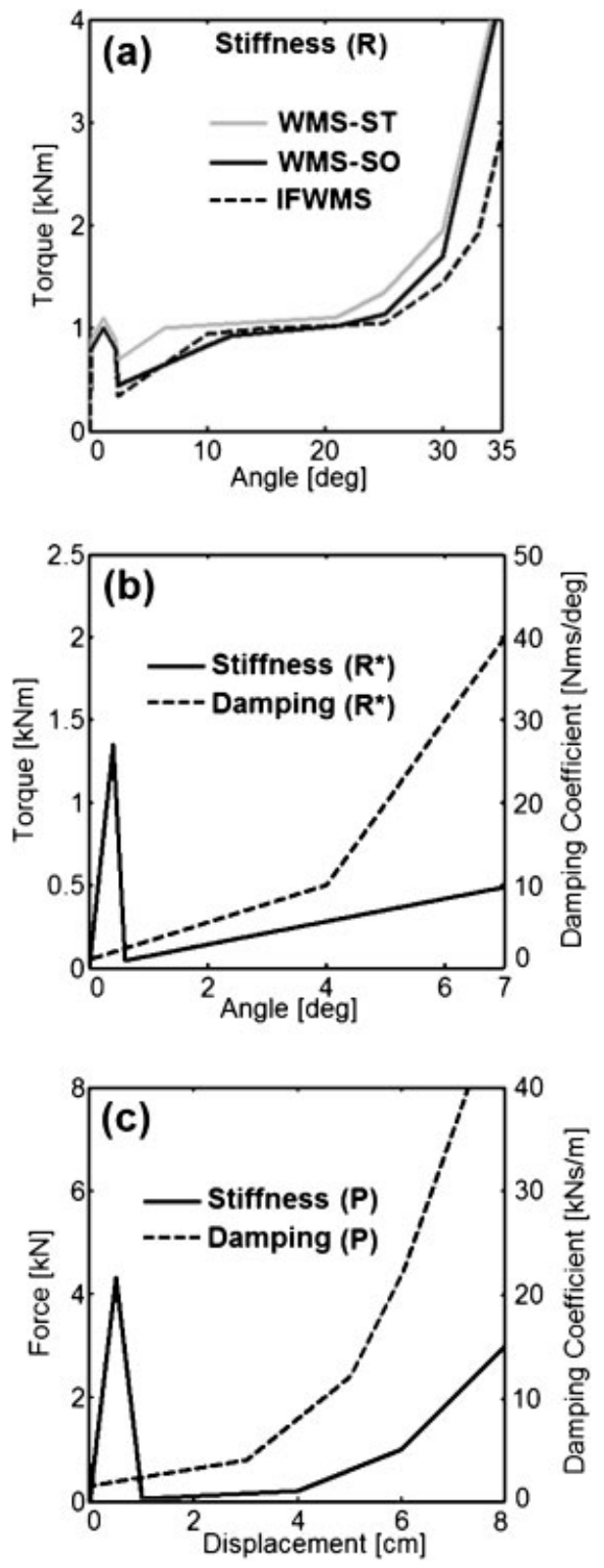

Fig. 5 The mechanical properties of the AWDs

the car during the rebound of the seat-pan, especially at higher severity rear impacts (see Fig. 9 later).

The foam-plate $\left(\mathrm{P}^{*}\right)$ is operational at all times. For a $\Delta \mathrm{V}$ less than $7 \mathrm{~km} / \mathrm{h}$, the foam-plate $\left(\mathrm{P}^{*}\right)$ and the $\mathrm{HR}$ are the only components which provide protection against whiplash. The operational ranges of the AWDs are dictated by the breakaway forces and/or torques, which are tabulated in Table 1.

\subsection{Mechanical properties of the head restraint HR}

The mechanical properties of the HR are adapted from the results of the impact tests conducted by
Table 1 Operational ranges of the AWDs

\begin{tabular}{llll}
\hline & $\begin{array}{lll}7 \mathrm{~km} / \mathrm{h} \leq \Delta \mathrm{V} \\
<10 \mathrm{~km} / \mathrm{h}\end{array}$ & $\begin{array}{l}10 \mathrm{~km} / \mathrm{h} \leq \Delta \mathrm{V} \\
\leq 13 \mathrm{~km} / \mathrm{h}\end{array}$ & $\begin{array}{l}\Delta \mathrm{V}> \\
13 \mathrm{~km} / \mathrm{h}\end{array}$ \\
\hline WMS-ST & $\mathrm{R}$ & $\mathrm{R}, \mathrm{P}$ & $\mathrm{R}, \mathrm{P}$ \\
WMS-SO & $\mathrm{R}$ & $\mathrm{R}, \mathrm{P}$ & $\mathrm{R}, \mathrm{P}$ \\
IFWMS & $\mathrm{R}$ & $\mathrm{R}, \mathrm{P}$ & $\mathrm{R}, \mathrm{P}, \mathrm{R}^{*}$ \\
\hline
\end{tabular}

Viano [20]. In these tests, the back cap of a Hybrid III dummy head was impacted vertically on different head restraints using a hydraulic material-testing machine, at an impact speed of $1.1 \mathrm{~m} / \mathrm{s}$. The displacement of the dummy head and the normal force generated by the head restraints were recorded. Figure 6 shows the mechanical properties of the HR, which represent the normal force versus penetration characteristics of an average head restraint in these impact tests. In Fig. 6, the penetration accounts for the net displacement of the head due to foam and structural deformation of the HR, thus the structural deformation is not modelled separately. When the penetration rate changes sign, the head loads and unloads the HR along a hysteresis slope until the corresponding loading and unloading curves are reached. This hysteresis model is shown in Fig. 6.

\section{EVALUATION OF THE REACTIVE CAR SEAT CONCEPTS}

\subsection{Seat design parameters and injury measures}

The head restraint HR is attached to all of the car seat models and it satisfies the minimum height requirement set by the European standard (UN-ECE Regulation No. 17) [4]. Nonetheless, an additional vertical height of $35 \mathrm{~mm}$ is added to compensate for spine straightening. This value corresponds to the average upward displacement of the first thoracic

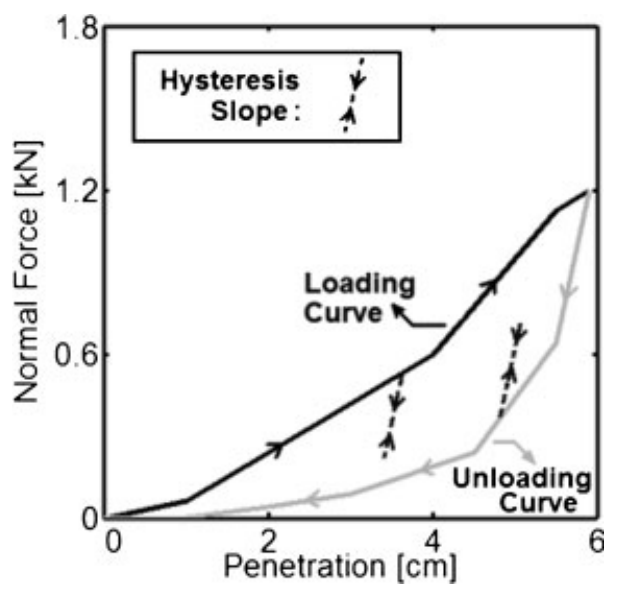

Fig. 6 The impact function for the HR 
vertebra (T1) as observed in the JARI volunteer sled tests [27]. Therefore, the top of the HR becomes level with the top of the head (see Fig. 1). It is considered that back-set values less than $45 \mathrm{~mm}$ could cause discomfort [34]. Hence, the back-set of HR is set to $60 \mathrm{~mm}$ to allow head comfort. This back-set value is within the range of a good head restraint geometry as specified by IIWPG [35].

In order to evaluate the dynamic performance of the car seat concepts, the assessment criteria of the EuroNCAP dynamic whiplash test are used. These are the upper neck rearward shear force $\left(\mathrm{Fsh}^{(-)}\right)$, upper neck tension force (Ftn), head restraint contact time $(\mathrm{HrCt}), \mathrm{T} 1$ forward acceleration $\left(\mathrm{T} 1_{\mathrm{x}-\mathrm{acc}}\right)$, head rebound velocity $\left(\mathrm{v}_{\mathrm{r}}\right)$, seat-back rotational deflection, $\mathrm{N}_{\mathrm{km}}$, and neck injury criterion (NIC) [6]. $\mathrm{N}_{\mathrm{km}}$ is an injury criterion which uses a combination of the shear force and moment acting at the occipital condyles (OC) [36]. NIC is associated with the formation of an S-shape-like deformation in the neck and is based on the relative acceleration and velocity between the OC and T1 [37]. S-shape-like deformation occurs as a result of head retraction relative to the upper torso during rear impact and it can cause abnormal segmental motions in the neck, causing unfavourable loading of the soft tissues and even pressure alterations [37] inside the cervical spinal canal. The criteria of the EuroNCAP whiplash test are a combination of the parameters used in the IIWPG and the Swedish National Road Administration (SNRA) whiplash tests [35, 38].

Whiplash injury mechanisms are still not completely understood and the injury criteria used in the EuroNCAP whiplash test are not fully proven by biomechanical research $[2,6,15]$. Therefore, EuroNCAP takes into consideration every plausible injury mechanism and criterion (or measure) that has been suggested and this is considered as a 'best practice' approach [2, 6]. Several researchers [39, 40] have indicated the lack of accurate injury risk curves for whiplash and expressed their concerns on some of the assessment criteria, tolerance levels (i.e. performance limits), and the rating system used by EuroNCAP. Schmitt and Muser [39], and Ikari et al. [41] suggested reduction and/or modification of the assessment criteria applied in the EuroNCAP whiplash test and they recommended that the criteria, which have strong biomechanical significance, should be used. EuroNCAP is considering further examination of the number of criteria in relation to the test costs [6].

EuroNCAP rates the car seats as good, marginal, or poor according to the total points they get from the whiplash test scoring system. Coloured bands are used for these three different ratings in order to raise public awareness and help the customers to understand the level of whiplash protection offered by the car seats in a practical manner [6]. The EuroNCAP rating is considered to be related to whiplash injury risk $[2,6]$ since recent studies have found a correlation between IIWPG and SNRA dynamic seat ratings and real-world whiplash-injury outcomes [21]. It should be emphasized that the EuroNCAP rating is an indication of relative injury-risk, but not absolute injury-risk, i.e. the EuroNCAP rating corresponds to the assesment of the relative performance of car seats in rear impacts. Therefore, EuroNCAP rating does not predict with complete certainty the severity of injury and even whether whiplash would definitely occur or not in various real-world accidents involving occupants of all types. Consequently, when a car earns a good rating in the EuroNCAP whiplash test, it means that its seat has the capability to perform better than the other car seats which earn marginal or poor ratings.

The EuroNCAP whiplash test has a complicated scoring system suitable for commercial seats. Therefore, in this study, the evaluations of the reactive car seat concepts are performed using the limit values specified in the IIWPG and SNRA dynamic rating systems, since this is considered to be the practical and suitable way to rate conceptual car seats for a wide range of crash severities. The selected limits for the seat design parameters and injury measures used in this study are listed in Table 2 .

The maximum allowable rearward displacements of the seat components are selected in line with the suggested values for other energy-absorbing car seat designs in the literature $[18,20,42,43]$. For the highest crash severity studied, the rotation at $\mathrm{R}^{*}$ and the seat-pan displacement at $\mathrm{P}$, denoted by $\Delta \theta_{\mathrm{R}^{*}}$ and $\Delta x_{\mathrm{SP}}$ respectively, are limited to $6.5^{\circ}$ and $6.4 \mathrm{~cm}$. In the EuroNCAP dynamic whiplash test, the limit for

Table 2 Limits for the dynamic rating of the car seat concepts (L-R: low risk; M-R: medium risk; H-R: high risk)

\begin{tabular}{lll}
\hline Parameter & Limits & Reference \\
\hline & & \\
Fsh $^{(-)}$, Ftn (N) & Fig. 7 & {$[35]$} \\
$\mathrm{HrCt}(\mathrm{ms})$ & $\leq 70 \mathrm{~ms}$ & {$[35]$} \\
$\mathrm{T} 1_{\mathrm{x} \text {-acc }}(\mathrm{g})$ & $\leq 9.5 \mathrm{~g}$ & {$[35]$} \\
$\mathrm{NIC}(\mathrm{m} / \mathrm{s})$ & $<15 \mathrm{~m} \mathrm{/s}$ & {$[37]$} \\
$\mathrm{N}_{\mathrm{km}}$ & $<1$ & {$[36]$} \\
$\Delta \theta_{\mathrm{SB}}(\mathrm{deg})$ & $<32 \mathrm{deg}$ & {$[18,20]$} \\
$\Delta \theta_{\mathrm{R}^{*}}(\mathrm{deg})$ & $<6.5 \mathrm{deg}$ & {$[20,42,43]$} \\
$\Delta x_{\mathrm{SP}}(\mathrm{cm})$ & $<6.4 \mathrm{~cm}$ & {$[20,42,43]$} \\
$\mathrm{V}_{\mathrm{r}}(\mathrm{m} / \mathrm{s})$ & $\mathrm{L}-\mathrm{R}:<4.5 \mathrm{~m} / \mathrm{s}$ & {$[38]$} \\
& $\mathrm{M}-\mathrm{R}: 4.5 \mathrm{to} 6 \mathrm{~m} / \mathrm{s}$ & \\
& $\mathrm{H}-\mathrm{R}:>6 \mathrm{~m} / \mathrm{s}$ & \\
\hline
\end{tabular}


the rotational deflection of the seat-back is specified as $32^{\circ}[6]$. Therefore the total change in seat-back (SB) angle, denoted by $\Delta \theta_{\mathrm{SB}}$, is restricted to $32^{\circ}$ to limit ramping and rearward displacement of the seat-back. It should be noted that $\Delta \theta_{\mathrm{SB}}$ is measured with respect to the inertial coordinate system $\mathrm{S}_{\mathrm{G}}$.

In TYPS seats, the rotational and translational (horizontal) displacements of the SB relative to the SP (due to deformation at the LRM), are denoted by $\Delta \theta_{\text {LRM }}$ and $\Delta x_{\mathrm{LRM}}$, respectively.

In rating the forces at the upper neck (i.e. occipital condyles or OC forces), the IIWPG neck force classification, as shown in Fig. 7, is used. It must be noted that this neck force classification is a statistical but not a biomechanical interpretation of upper neck forces. These criteria were determined by studying the distribution of upper neck forces based on the tests conducted by the IIWPG. In these tests, the 2004 model year car seats with good geometry were subjected to the IIWPG standard crash pulse $\left(\Delta \mathrm{V}=16 \mathrm{~km} / \mathrm{h}, \mathrm{a}_{\text {mean }}=5 \mathrm{~g}, \quad \mathrm{a}_{\text {peak }}=10 \mathrm{~g}\right)$ using the BioRID II dummy. It is known that human models (computational or mechanical) show varied responses under the same rear-impact test conditions [16] since they do not have identical mechanical properties. Hence, BioRID II's response to loading by the seat-back and the head restraint will differ to some extent in comparison with the human model used in this study, but the IIWPG neck force classification can still be used for comparing better and worse car seat designs by employing the human model in this study.

\subsection{Test procedure}

In order to assess the performance of the reactive car seat concepts, the human model is positioned as shown in Fig. 1 to adopt a posture similar to the one

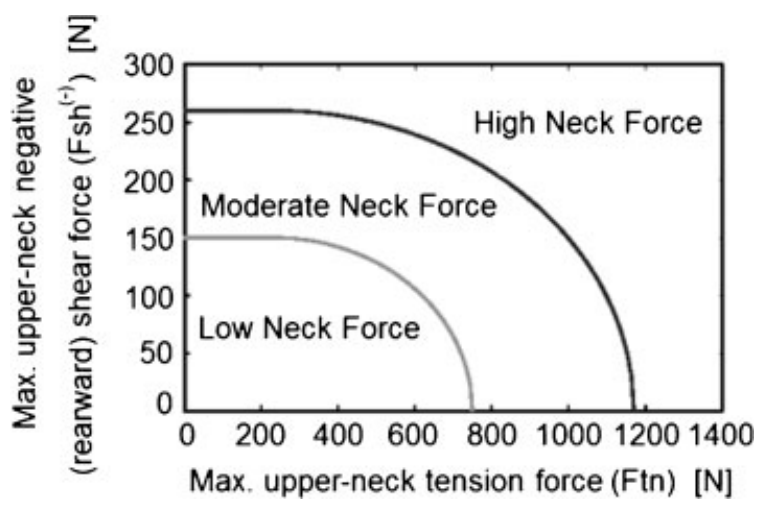

Fig. 7 IIWPG neck force classification (adapted from IIWPG [35]) practiced in whiplash dynamic tests [35]. As in the JARI sled tests, no seatbelt is used and the initial seat back angle is set to $20^{\circ}$ from the vertical.

In the EuroNCAP dynamic whiplash test, three different crash pulses are employed: a low-severity trapezoidal pulse $\operatorname{TR}(16) \quad\left(\Delta \mathrm{V}=16 \mathrm{~km} / \mathrm{h}, \mathrm{a}_{\text {mean }}=\right.$ $4.5 \mathrm{~g}, \quad \mathrm{a}_{\text {peak }}=5 \mathrm{~g}$ ), a medium-severity triangular (or sinusoidal) pulse $\mathrm{SN}(16)\left(\Delta \mathrm{V}=16 \mathrm{~km} / \mathrm{h}, \mathrm{a}_{\text {mean }}=5 \mathrm{~g}\right.$, $\mathrm{a}_{\text {peak }}=10 \mathrm{~g}$ ), and a high-severity trapezoidal pulse $\operatorname{TR}(24)\left(\Delta \mathrm{V}=24 \mathrm{~km} / \mathrm{h}, \mathrm{a}_{\text {mean }}=6.5 \mathrm{~g}, \mathrm{a}_{\text {peak }}=7.5 \mathrm{~g}\right)$ [2]. In this study, the simulations are run for a wider range of crash pulses as given in Table 3, including the EuroNCAP pulses, in which sinusoidal and trapezoidal type pulses are denoted by SN and TR respectively, and the highest severity pulse is represented by HS. Sinusoidal type pulses are the most common type within the crash severity range where the majority of rear-end collisions occur. The trapezoidal pulses are not found to be representative of the recorded crash pulses either in laboratory rear-impact tests (car-to-car and barrier-to-car) or in real-world rear-end crashes involving current pro- duction cars [41, 44].

The performances of the reactive car seat concepts are also compared with those of the typical car seat models TYPS-B1 and TYPS-G2. However, for this comparison, the simulations are run only for the crash pulse $\mathrm{SN}(16)$ since the mechanical properties of the LRM in the TYPS seats are derived from the work of Eriksson [32], in which the models of typical car seats were tuned to the validation sled tests using two crash pulses of $\Delta \mathrm{V} \approx 17 \mathrm{~km} / \mathrm{h}$, and the severity of $\mathrm{SN}(16)$ is similar to those of the two pulses.

In the simulations, the maximum $\mathrm{T} 1$ forward acceleration is taken as the highest acceleration of $\mathrm{T} 1$ in the $\mathrm{x}$-direction, as expressed in the inertial coordinate system $\mathrm{S}_{\mathrm{G}}$ (see Fig. 1). For the head rebound velocity, the maximum resultant head velocity with respect to the sled (see Fig. 1) is taken during the period in which the head starts to rebound from the head restraint and also moves in the forward $(+x)$ direction relative to the sled. This definition is in accordance with the head rebound velocity measurement in the EuroNCAP whiplash test procedure [6].

The head coordinate system is located at the head centre of gravity, as shown in Fig. 1. In the human model, the positive shear and the positive normal forces acting on the head at the OC (i.e. upper neck) are defined in the directions of $+\mathrm{x}$ and $+\mathrm{z}$ axes of the head coordinate system respectively. The OC tension force acting on the head (Ftn) is negative by definition, and the upper neck rearward shear force 
Table 3 The list of crash pulses used in the simulations

\begin{tabular}{|c|c|c|c|c|c|c|c|c|c|}
\hline Pulse & $\Delta \mathrm{V}(\mathrm{km} / \mathrm{h})$ & $\mathbf{a}_{\text {mean }}(\mathrm{g})$ & $a_{\text {peak }}(g)$ & Ref. & Pulse & $\Delta \mathrm{V}(\mathrm{km} / \mathrm{h})$ & $a_{\text {mean }}(g)$ & $a_{\text {peak }}(g)$ & Ref. \\
\hline $\mathrm{SN}(4.5)$ & 4.5 & 1.86 & 4.5 & [29] & TR(16) & 16 & 4.5 & 5 & {$[2]$} \\
\hline $\mathrm{SN}(8.4)$ & 8.4 & 3.3 & 8.7 & [29] & SN(16) & 16 & 5 & 10 & {$[2]$} \\
\hline $\mathrm{SN}(9.4)$ & 9.4 & 3.1 & 11.7 & [29] & $\mathrm{SN}(20.5)$ & 20.5 & 5.2 & 10.6 & [30] \\
\hline SN(11) & 11 & 4.4 & 9.6 & [29] & $\mathrm{TR}(24)$ & 24 & 6.5 & 7.5 & {$[2]$} \\
\hline SN(13) & 13 & 4.7 & 10.3 & [29] & $\mathrm{HS}(30)$ & 30 & 6.8 & 26.5 & [20] \\
\hline
\end{tabular}

(defined by the IIWPG force classification) is taken as the negative OC shear force $\left(\mathrm{Fsh}^{(-)}\right)$acting on the head. Hence the OC shear force, acting on the head in the $+x$ direction of the head coordinate system, is defined as the positive OC shear force $\left(\mathrm{Fsh}^{(+)}\right)$.

In order to simulate the frictional resistance between a typical car-occupant and typical car seat upholstery, a Coulomb friction coefficient of 0.35 is used in the simulations for all contacts between the human and the seat models. This value is derived from the work of Verver [31], who conducted experiments to estimate an average friction coefficient value to be used in modelling the interaction between an occupant and a typical car seat.

\section{RESULTS}

In order to give an insight into the behaviour of the seat components, the responses of the AWDs of IFWMS, when subjected to the crash pulse $\mathrm{SN}(16)$, are presented in Fig. 8. The corresponding response of the human model is shown in Fig. 9(c).

During the first $50 \mathrm{~ms}$ of the impact, the foam-plate (with the aid of $\mathrm{P}^{*}$ ) allows the human model to sink into the seat-back structure by $2.8 \mathrm{~cm}$ without any rotation of the seat-back, as shown in Fig. 8. Therefore, between 0 to $50 \mathrm{~ms}$, the seat-pan starts to move backwards slowly relative to the sled (see Fig. 1) and P becomes fully operational by the end of this period

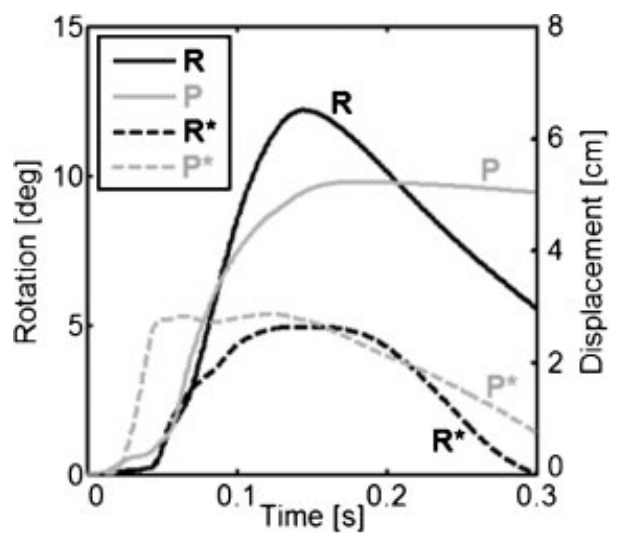

Fig. 8 AWD responses (seat: IFWMS; pulse: $\mathrm{SN}(16)$ ) while $\mathrm{R}$ (recliner) and $\mathrm{R}^{*}$ are still not fully operational. At around $50 \mathrm{~ms}$, the foam-plate bottoms out. Starting from $50 \mathrm{~ms}$, the seat-pan starts to move backwards rapidly and then $\mathrm{R}$ and $\mathrm{R}$ * both become operational at around $55 \mathrm{~ms}$. At $70 \mathrm{~ms}$, the seat-pan reaches a displacement of $2.2 \mathrm{~cm}$. Between 50 and $70 \mathrm{~ms}$ the anti-clockwise rotation at $\mathrm{R}$ and the clockwise rotation at $\mathrm{R}^{*}$ are of similar magnitude, but they cancel each other out. Consequently, the seat moves backwards initially with negligible seat-back rotation. After $70 \mathrm{~ms}$, the displacement rates are rapid for all the seat components (except the foam-plate) until their respective maximum displacements are reached at around $145 \mathrm{~ms}$. Between 145 and $300 \mathrm{~ms}$, the seat components rebound gently while the inner frame (controlled by $\mathrm{R}^{*}$ ) retracts completely to decrease the loading on the head and neck as the head rebounds from the HR. For the seats WMS-ST and WMS-SO, the AWDs behave in a very similar way.

The interaction of the human model with IFWMS, when subjected to the crash pulse $\mathrm{SN}(16)$, is shown in Fig. 9(c). The neck deformation is insignificant throughout the impact as observed from the simulations. HR contact occurs at $58 \mathrm{~ms}$, followed by the formation of the most prominent S-shape-like deformation (i.e. head retraction) at $75 \mathrm{~ms}$. At around $125 \mathrm{~ms}$ the normal force applied by the HR on the head becomes maximum, hence the shear force at the $\mathrm{OC}$ reaches its largest value. From then on, the head unloads the HR until it completely loses contact with it at $250 \mathrm{~ms}$. The peak compression force at the $\mathrm{OC}$ occurs at around $50 \mathrm{~ms}$ as a consequence of spine straightening. The foam-plate also bottoms out at around $50 \mathrm{~ms}$ as the torso has fully sunk into the seat-back structure. This causes a temporary increase in the normal force applied by the seat-back on the torso, causing spine straightening and a peak in the compression force. For all the reactive car seat concepts and at all crash severities, the values of the peak compression force resulting from spine straightening are within the range of the peak compression forces sustained by the volunteers in the JARI sled tests [27].

The performance of IFWMS at five different crash pulses is presented in Figs 9(a) to (e). For each pulse, Fig. 9 shows frozen frames from the simulations at 


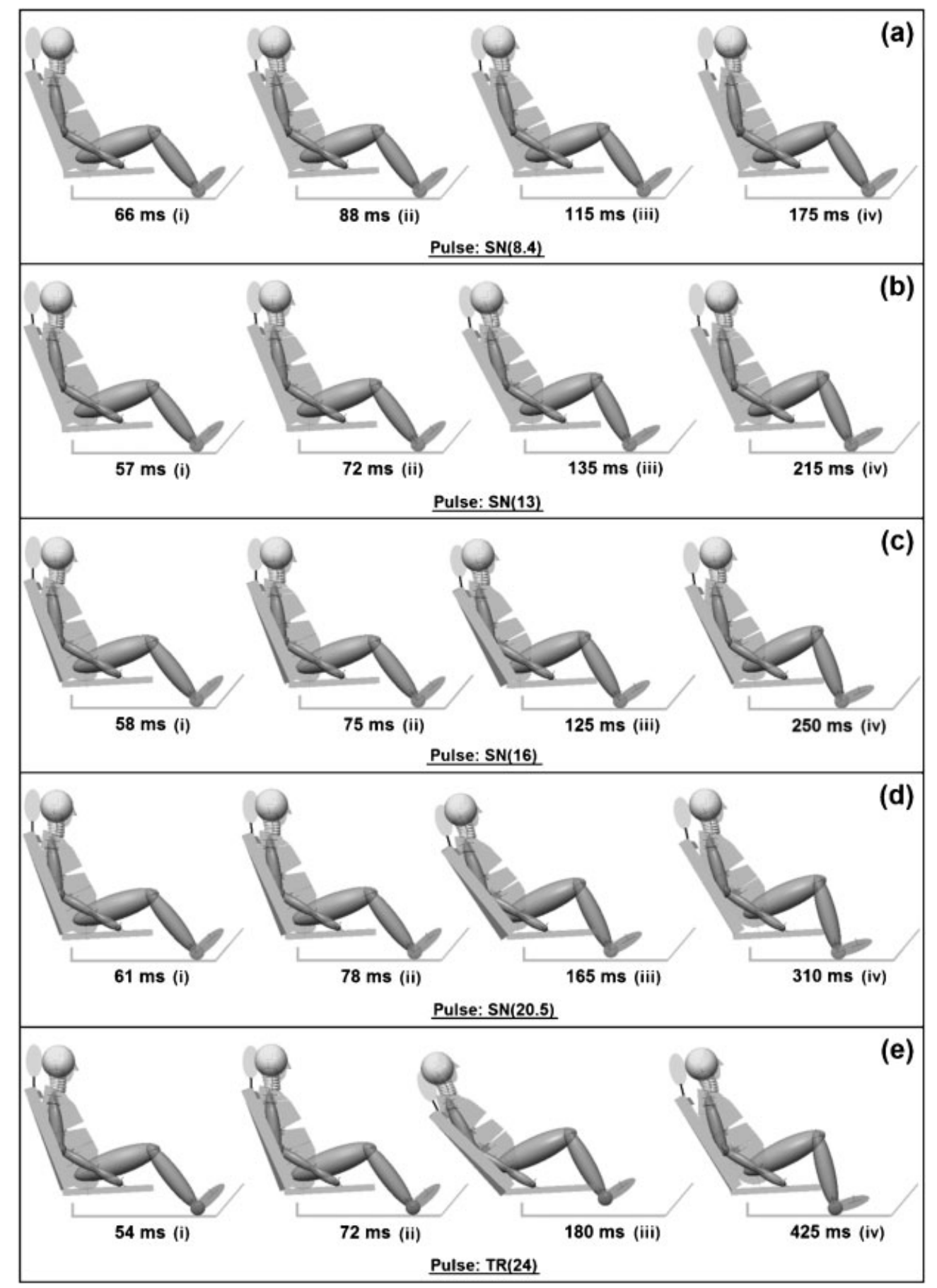

Fig. 9 Performance of IFWMS at different crash severities

four instances: instant (i) is when the head first contacts the HR; instant (ii) is when the most prominent S-shape-like deformation develops; instant (iii) is when the largest seat-back-rotation occurs (the maximum penetration of the head into the HR also occurs at around this moment); and instant (iv) is when the head just leaves the HR. Some selected results, regarding the injury measures, are given later in Figs 10 to 13 which include upper neck rearward shear force $\left(\mathrm{Fsh}^{(-)}\right), \mathrm{N}_{\mathrm{km}}$, and NIC.

\section{DISCUSSION}

7.1 Performance of the reactive car seat concepts On the whole, all of the reactive car seat concepts satisfy successfully the criteria listed in Table 2 at all 


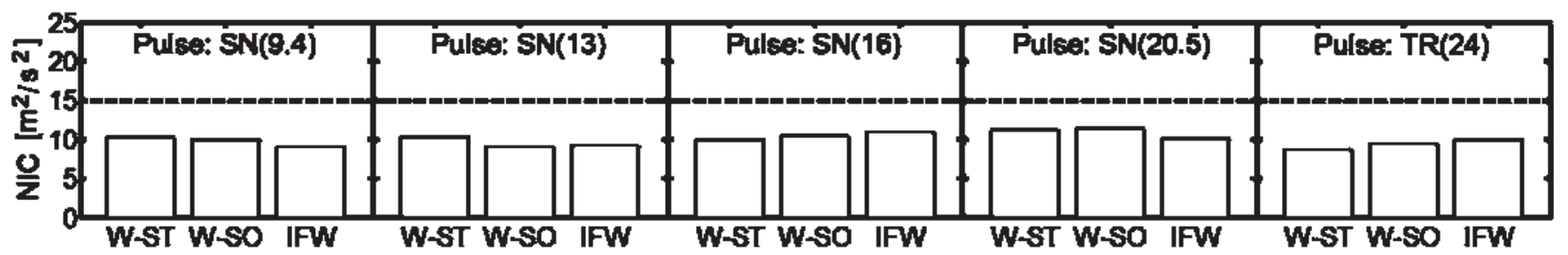

Fig. 10 NIC responses at selected crash severities

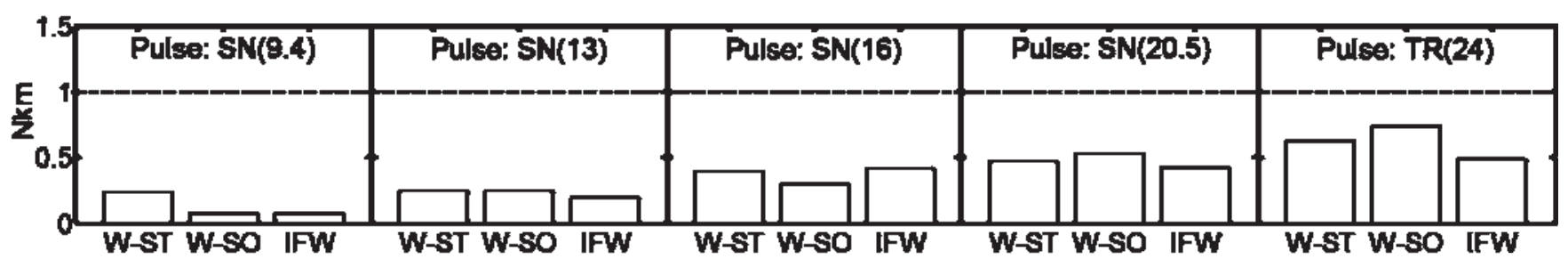

Fig. $11 \mathrm{~N}_{\mathrm{km}}$ responses at selected crash severities

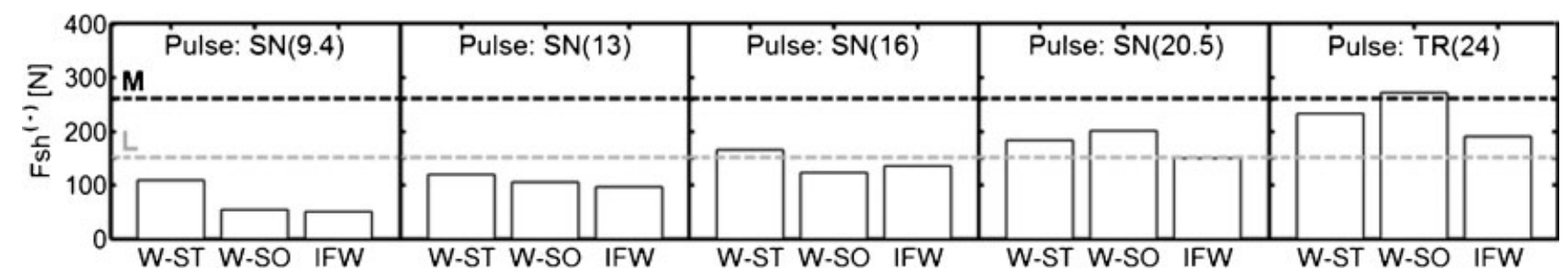

Fig. $12 \mathrm{Fsh}^{(-)}$responses at selected crash severities (force limits: L, low; M, medium)
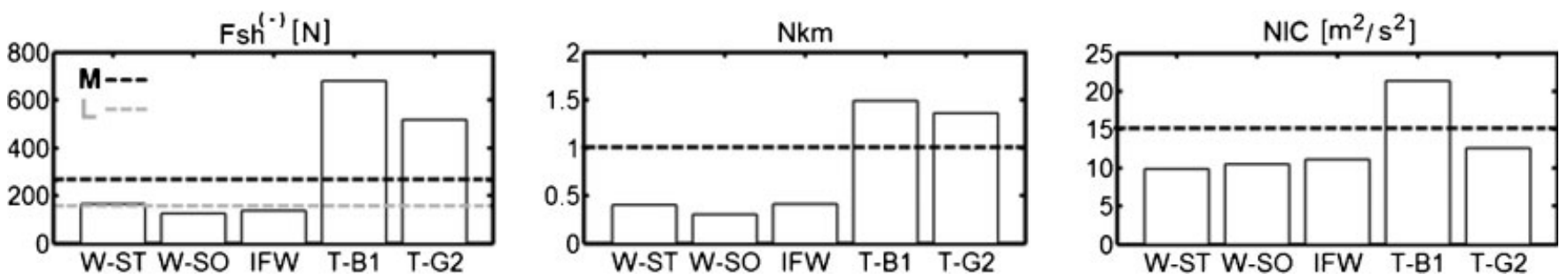

Fig. 13 Comparison of seat responses $\left(\mathrm{Fsh}^{(-)}, \mathrm{N}_{\mathrm{km}}, \mathrm{NIC}\right)$ to the crash pulse $\mathrm{SN}(16)$ (force limits: L, low; M, medium)

crash severities. The maximum T1 forward accelerations are less than $7.85 \mathrm{~g}$, which is lower than the recommended limit (9.5g) specified for energyabsorbing seats. The OC tension forces (Ftn) are less than $260 \mathrm{~N}$, which is considered to be low (see Fig. 7). Generally, early head restraint contact times ( $\mathrm{HrCt} \leq 75 \mathrm{~ms}$ ) are achieved considering that the suggested contact time at the IIWPG standard crash pulse $(\mathrm{SN}(16))$ is $70 \mathrm{~ms}$. The only exception happens for the weakest (hence not injurious) pulse $\mathrm{SN}(4.5)$, for which $\mathrm{HrCt}$ is $87 \mathrm{~ms}$. For $\Delta \mathrm{V}>13 \mathrm{~km} / \mathrm{h}$, IFWMS has significantly earlier contact times (ranging from 7 to $15 \mathrm{~ms}$ on average) than WMS-ST and WMS-SO because the counter-rotation of the inner frame at $\mathrm{R}^{*}$ reduces the dynamic back-set and the effective seatback angle.

The maximum NIC values are less than $11.5 \mathrm{~m}^{2} / \mathrm{s}^{2}$ and, as shown in Fig. 10, this is lower than the proposed injury threshold value of $15 \mathrm{~m}^{2} / \mathrm{s}^{2}$. Sshape-like deformation (i.e. head retraction) is not significant at all crash severities, as observed from the simulations. The positive OC-shear forces $\left(\mathrm{Fsh}^{(+)}\right)$are quite low $(<55 \mathrm{~N})$, which also indicates that head retraction is successfully limited. As shown in Fig. 11, the $\mathrm{N}_{\mathrm{km}}$ values are less than 0.76 , which is lower than the injury threshold value of 1 . Figure 12 
presents the largest values of the negative OC-shear forces $\left(\mathrm{Fsh}^{(-)}\right)$produced by the reactive car seat concepts at selected crash severities. In general, $\mathrm{Fsh}^{(-)}$values are either low (less than $150 \mathrm{~N}$ ) or moderate (between $150 \mathrm{~N}$ and $260 \mathrm{~N}$ ) in magnitude. For the seats WMS-ST and IFWMS, the moderate $\mathrm{Fsh}^{(-)}$limit is reached only at the highest severity pulse $\operatorname{HS}(30)$. However, for the seat WMS-SO, $\mathrm{Fsh}^{(-)}$ values are slightly over the moderate $\mathrm{Fsh}^{(-)}$limit for both high severity $\mathrm{TR}(24)$ and $\mathrm{HS}(30)$ pulses. In comparison with WMS-ST, the seat WMS-SO produces lower $\mathrm{Fsh}^{(-)}$for $\Delta \mathrm{V}<20.5 \mathrm{~km} / \mathrm{h}$, but higher $\mathrm{Fsh}^{(-)}$for $\Delta \mathrm{V} \geq 20.5 \mathrm{~km} / \mathrm{h}$. On the other hand, IFWMS achieves a more balanced and better performance with regard to $\mathrm{Fsh}^{(-)}$values. As a seat-belt is not used, the occupant retention is solely provided by the seat-back. This puts a limit on the seatback rotation considering that the interference with the rear seat and the rear occupant should be limited at the same time.

It should be noted that in addition to NIC, the $\mathrm{Fsh}^{(-)}$and $\mathrm{N}_{\mathrm{km}}$ responses are specifically presented in Figs 11 to 13, since these two measures are able to distinguish between the reactive car seat concepts with more precision. Similarly, using a series of sled tests, Schmitt and Muser [39] made a sensitivity analysis of the criteria in the EuroNCAP dynamic whiplash test and they demonstrated that $\mathrm{N}_{\mathrm{km}}$, NIC, and $v_{r}$ formed a sufficient set of criteria that was able to rate the rear-impact performance of seats accurately. They noted that $\mathrm{Fsh}^{(-)}, \mathrm{N}_{\mathrm{km}}$, and NIC had strong biomechanical significance, but the remaining criteria were either redundant or had weaker biomechanical significance.

The rearward displacements of the seat components do not exceed the limits set in Table 2, even at the highest severity pulse $\mathrm{HS}(30)$. Foam-plate displacement $\left(\Delta_{\mathrm{P}^{*}}\right)$ is around $3.2 \mathrm{~cm}$ at most. No seatbelt is used but occupant retention is still provided. The head restraint HR is high enough and the ramping of the body has not caused hyperextension in the neck.

The rebound velocities of the head and torso are low since the forward rebound of the seat components is limited. For all the reactive car seat concepts, $\mathrm{V}_{\mathrm{r}}$ values are less than $1.5 \mathrm{~m} / \mathrm{s}$ at all crash severities and hyperflexion is not observed in the simulations.

\subsection{Comparison of the reactive car seat concepts with the TYPS seats}

Figure 13 shows that the responses of the reactive car seat concepts and the TYPS seats to the IIWPG standard crash pulse (SN(16)) are quite different, despite having the same head restraint with the same geometry. The comparison between WMS and TYPS seats, for the pulse $\mathrm{SN}(16)$, is also shown in Fig. 14, using frozen frames from the simulations at $40 \mathrm{~ms}$ : (i) just before the human model fully sinks into the seat-back structure; the instant (ii) when the head first contacts the HR; the instant (iii) when the largest seat-back-rotation occurs (the maximum deformation at the HR also occurs at around this moment); and the instant (iv) when the head just leaves the HR.

It can be seen in Fig. 13 that the head interacts with the HR severely in the TYPS seats and this leads to increased tension (Ftn) forces (around $400 \mathrm{~N}$ ) and high $\mathrm{Fsh}^{(-)}$(negative OC-shear forces) values. Thus, $\mathrm{N}_{\mathrm{km}}$ is around 1.4 for the TYPS seats and this is above the injury threshold.

TYPS-B1 as a very stiff recliner mechanism structure $\left(\Delta \mathrm{h}_{\mathrm{LRM}}=4.76^{\circ}, \quad \Delta \mathrm{x}_{\mathrm{LRM}}=1.73 \mathrm{~cm}\right)$ and it loads the torso rapidly and excessively. Thus, the head is strongly thrown backward relative to the seat, causing relatively early head support. However, TYPS-B1 produces very high $\mathrm{T} 1_{\mathrm{x} \text {-acc }}(19.1 \mathrm{~g})$ and NIC $\left(21.3 \mathrm{~m}^{2} / \mathrm{s}^{2}\right)$ values, well above the threshold values.

TYPS-G2 has a softer recliner mechanism structure $\left(\Delta \mathrm{h}_{\mathrm{LRM}}=15.9^{\circ}, \Delta \mathrm{x}_{\mathrm{LRM}}=2.62 \mathrm{~cm}\right)$ such that the seat-back begins to rotate early and rapidly after the onset of the impact, leading to poor support of the head and torso throughout the impact. Hence, the head flexes considerably relative to the upper torso and head restraint contact time is extended excessively. TYPS-G2 produces acceptable NIC (12.6 $\left.\mathrm{m}^{2} / \mathrm{s}^{2}\right)$ but high $\mathrm{T} 1_{\mathrm{x} \text {-acc }}(13.5 \mathrm{~g})$ values. As the head is not supported early and effectively enough, the loading on the head and neck is still high.

\subsection{Qualities of the reactive car seat concepts}

The AWDs absorb the crash energy collaboratively as they successively become operational once the breakaway torques and/or forces are exceeded. The relatively small breakaway torque at the recliner (R) enables the torso to sink into the seat-back structure without excessive rotation of the seat-back at the start of the impact. Therefore, the breakaway torque at the recliner is one of the design features that enables the head restraint to support the head effectively. The seat-backs of the reactive car seat concepts are designed to be yielding at the beginning, but they become progressively resistant to larger rotations, hence limiting the rearward displacement at higher crash-severities. 


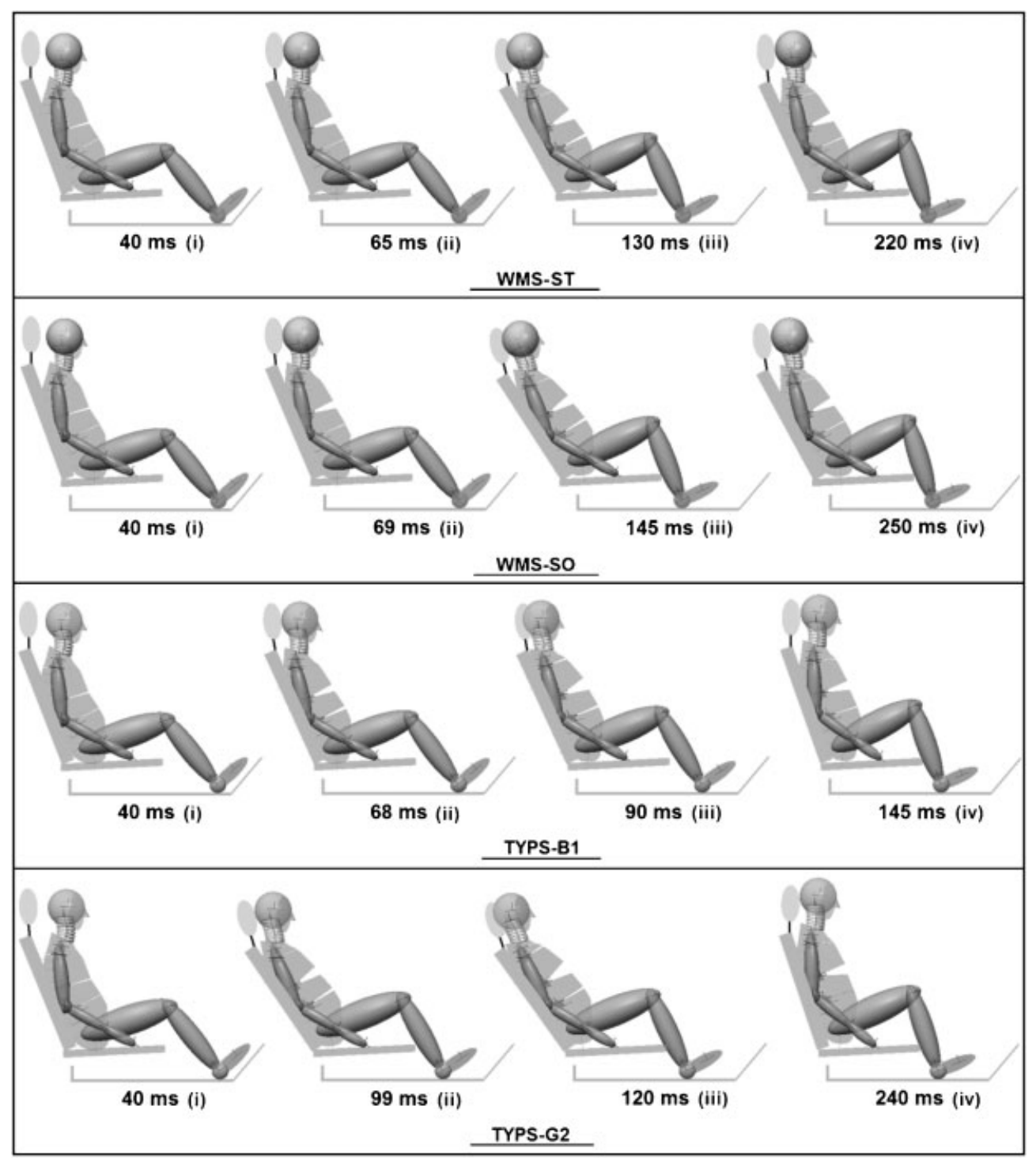

Fig. 14 Comparison of seat responses (WMS versus TYPS) to the crash pulse SN(16)

For all the reactive car seat concepts, between 7 and $10 \mathrm{~km} / \mathrm{h}$ of $\Delta \mathrm{V}$, the AWD situated at the recliner (R) is operational only. Hence, among all the AWDs, only $\mathrm{R}$ is involved in energy absorption. This imparts a yielding behaviour to the seat-back at lower crash severities, thus, at around $10 \mathrm{~km} / \mathrm{h}$ of $\Delta \mathrm{V}$, the rotation of the seat-back becomes as high as $5^{\circ}$ on average. Lower severity impacts $(\Delta \mathrm{V}<15 \mathrm{~km} / \mathrm{h})$ are much more frequent and a controlled yielding action of the seat-back is considered to offer better protection at such severities for vulnerable (e.g. older) occupants [10], including cases where there is inadequate support of the head by the head restraint [22].

For the seats WMS-ST and WMS-SO, the translational AWD placed under the seat-pan, denoted by $\mathrm{P}$, becomes operational after $10 \mathrm{~km} / \mathrm{h}$ of $\Delta \mathrm{V}$. Hence the
AWDs $\mathrm{R}$ and $\mathrm{P}$ are both involved in energy absorption and this controls the rotation of the seat-back effectively, preventing excessive rotation at the recliner $(\mathrm{R})$.

For the seat IFWMS, the AWDs $\mathrm{R}$ and $\mathrm{P}$ are both operational for a $\Delta \mathrm{V}$ between 10 and $13 \mathrm{~km} / \mathrm{h}$. For higher crash severities, the rotational AWD $\mathrm{R}^{*}$ becomes operational as well. IFWMS combines the favourable properties of the car seat concepts with the softer (WMS-SO) and the stronger (WMS-ST) recliners. IFWMS behaves like WMS-SO for pulses up to $\mathrm{SN}(16)$, but then behaves more like WMS-ST for the higher severity pulses. This can be seen in the $\mathrm{N}_{\mathrm{km}}$ and $\mathrm{Fsh}^{(-)}$responses shown in Figs 11 and 12 . Therefore, IFWMS is comparatively the better seat, as it shows a more balanced and better performance at all crash severities. IFWMS achieves this with the 
aid of the inner-frame rotation at $\mathrm{R}^{*}$. Hence, it can be said that IFWMS offers a solution that resolves the conflict between stiff and yielding seats [20].

The rotation at $\mathrm{R}^{*}$ activates the inner frame and this helps IFWMS to obtain more reduction in dynamic back-set while the torso conforms to the seat-back. In IFWMS, the characteristics of $\mathrm{R}^{*}$ are adjusted so that the inner-frame ( $\mathrm{SB}$ ) rotation (at $\mathrm{R}^{*}$ ) is accompanied by a sufficient amount of outer-seatback-frame (OF) rotation at $\mathrm{R}$ in order to avoid increasing excessively the loading on the upper torso in any case. Considering the forces applied by the human body on the seat-back, the rotation axis of $\mathrm{R}^{*}$ is placed in the upper half of the seat-back (closer to the top edge) so that the necessary amount of torque around the rotation axis of $\mathrm{R}^{*}$ is generated to make the inner frame (SB) rotate in the opposite direction relative to the outer seat-back frame (OF) in the first $140 \mathrm{~ms}$ of the impact before the inner frame retracts in the later phases (see Figs 2 and 8). Placing the rotation axis of $\mathrm{R}^{*}$ closer to the top edge of the seatback also accommodates occupants of varying stature. Occupants, especially the unbelted ones, can ramp up the seat-back significantly during rear impact and as a result more portions of the torso may travel above the rotation axis of $\mathrm{R}^{*}$. Placing the rotation axis of $\mathrm{R}^{*}$ closer to the top edge of the seat-back enables IFWMS to work more reliably and effectively at all crash severities since the rotation of the inner frame becomes less sensitive to ramping effects and variations in occupant stature. Hence, considering the position of the rotation axis of $\mathrm{R}^{*}$, the design of IFWMS is simple and robust.

In IFWMS, the rapid rotation at the recliner $(\mathrm{R})$ is compensated by the rotation at $\mathrm{R}^{*}$, hence at higher crash severities (i.e. $\Delta \mathrm{V}>13 \mathrm{~km} / \mathrm{h}$ ), the seat-back (i.e. inner frame) is not allowed to rotate early and excessively during the impact and HR contact is not delayed. This behaviour of IFWMS is exemplified in Figs 15 and 16 by comparing the responses of IFWMS and WMS-SO. Figure 15 shows the seat-back rotations of IFWMS and WMS-SO for $\Delta \mathrm{V}>13 \mathrm{~km} / \mathrm{h}$. Figure 16 shows frozen frames from the simulations in the first $75 \mathrm{~ms}$ of the impact when IFWMS and WMS-SO are subjected to the crash pulse $\mathrm{SN}(20.5)$ (the seat-backs of IFWMS and WMS-SO are shown in dark and light grey respectively). Up until $45 \mathrm{~ms}$, seat-back rotation is negligible for both IFWMS and WMS-SO since the torso is simply sinking into the seat-back structure with the aid of the foam-plate. HR contact occurs at $60 \mathrm{~ms}$ and $75 \mathrm{~ms}$ for IFWMS and WMS-SO respectively. It can be seen that at higher crash severities, WMS-SO does not perform as well as IFWMS since the seat-back of WMS-SO rotates more rapidly and less effectively. In IFWMS, the overall motion of the seatback is such that the seat-back purely translates up until $70 \mathrm{~ms}$ and the dynamic back-set is not allowed to increase. IFWMS has $\mathrm{HrCt}$ which are $12-15 \mathrm{~ms}$ earlier than those of WMS-SO for $\Delta \mathrm{V}>13 \mathrm{~km} / \mathrm{h}$.

Unlike the reactive and pro-active head restraint designs in the market, IFWMS achieves early head restraint contact without depending on the forward movement of the HR relative to the top of the seatback. Instead, in IFWMS, the idea is to achieve earlier head restraint contact through prompt control of the rotation of the seat-back. It should be noted that the inner frame (SB) is actuated by the whole torso of the occupant once the foam-plate bottoms out. This is different from the typical reactive head restraint designs in the market, in which the upper torso sinks into the upper seat-back foam and loads a plate to move the head restraint forward mechanically.

\section{CONCLUSIONS}

This paper presents three reactive car seat concepts, designed to mitigate whiplash injuries for a wide range of crash severity through coordinated motion of seat components. The proposed car seat concepts
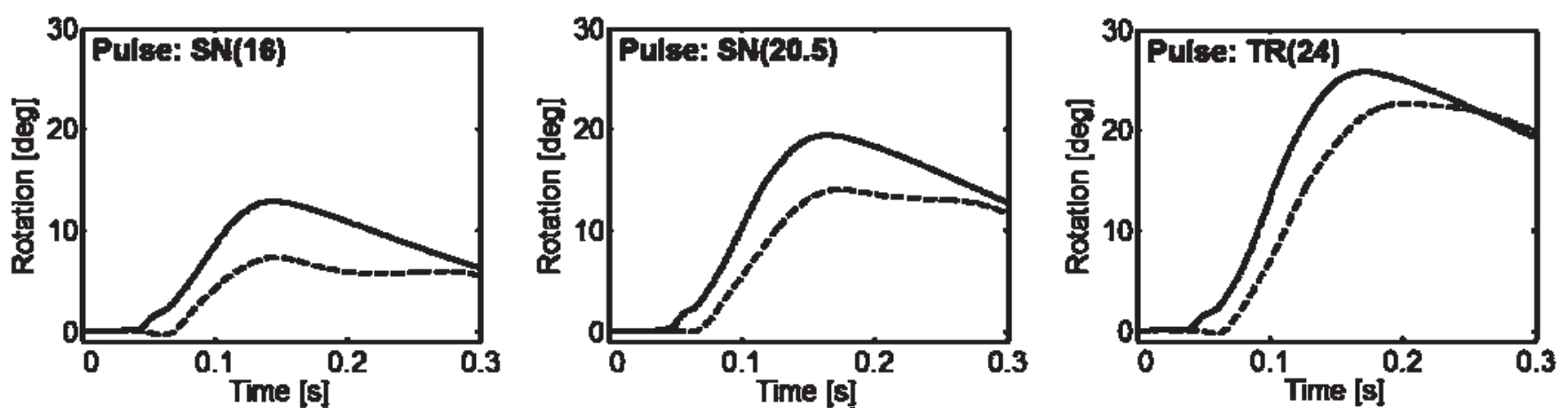

Fig. 15 Comparison of seat-back rotation at different crash severities (WMS-SO: solid line; IFWMS: dashed line) 


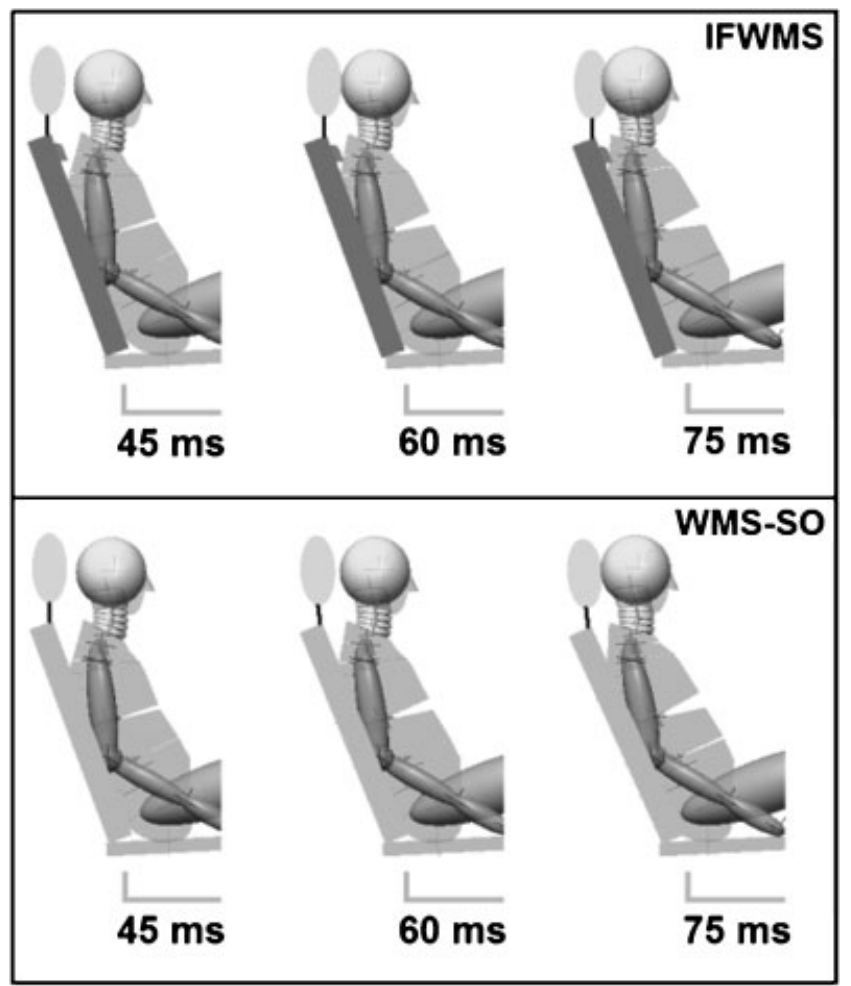

Fig.16 Seat-back response in the first $75 \mathrm{~ms}$ of the impact (IFWMS versus WMS-SO, pulse: $\mathrm{SN}(20.5)$ )

are reusable after a rear-end impact. The simulations have shown that the proposed car seat concepts clearly represent a significant improvement over the typical car seat models. Therefore, the structural characteristics of the seat have played a pivotal role in whiplash mitigation rather than the HR with good geometry. It has been demonstrated that the reactive car seat concepts can adapt themselves to different crash severities using passive AWDs so that the seatback and the HR work together effectively. Among the proposed concepts, the IFWMS seat provides the optimum neck protection at all crash severities. IFWMS achieves this performance with the aid of the AWD at R*, which controls the rotation of the seatback more effectively and provides relatively earlier head restraint contact. Hence, the reactive car seat concepts developed in this study should provide the basis for future whiplash-mitigating car seat designs that are capable of showing robust performance at different crash severities.

\section{REFERENCES}

1 Eis, V., Fay, P., and Sferco, R. A detailed analysis of the characteristics of European rear impacts. In
Proceedings of the 19th International Technical Conference on Enhanced safety of vehicles, Washington DC, USA, 6-9 June 2005, paper 05-0385-O (National Highway Traffic Safety Administration, Washington, DC).

2 Avery, M., Giblen, E., Weekes, A. M., and Zuby, D. S. Developments in dynamic whiplash assessment procedures. In Proceedings of the International Conference on Neck injuries in road traffic and prevention strategies, Munich, Germany, 5-6 November 2007, paper 15 (TÜV SÜD Akademie $\mathrm{GmbH}$, Munich).

3 Avery, M. and Weekes, A. M. Autonomous braking systems and their potential effect on whiplash injury reduction. In Proceedings of the 21st International Technical Conference on Enhanced safety of vehicles, Stuttgart, Germany, 15-18 June 2009, paper 09-0328 (National Highway Traffic Safety Administration, Washington, DC).

4 Edwards, M., Smith, S., Zuby, D. S., and Lund, A. $\mathrm{K}$. Improved seat and head restraint evaluations. In Proceedings of the 19th International Technical Conference on Enhanced safety of vehicles, Washington DC, USA, 6-9 June 2005, paper 05-0374-O (National Highway Traffic Safety Administration, Washington, DC).

5 Farmer, C. M., Zuby, D. S., Wells, J. K., and Hellinga, L. A. Relationship of dynamic seat ratings to real-world neck injury rates. Traffic Injury Prevention, 2008, 9(6), 561-567.

6 van Ratingen, M., Ellway, J., Avery, M., Gloyns, P., Sandner, V., and Versmissen, T. The EuroNCAP whiplash test. In Proceedings of the 21st International Technical Conference on Enhanced safety of vehicles, Stuttgart, Germany, 15-18 June 2009, paper 09-0231 (National Highway Traffic Safety Administration, Washington, DC).

7 Hell, W., Langwieder, K., and Walz, F. Reported soft tissue neck injuries after rear-end car collisions. In Proceedings of the International IRCOBI Conference, Göteborg, Sweden, 16-18 September 1998, pp. 261-274 (International Research Council on Biomechanics of Injury, Zurich).

8 Galli, R. M. and Digges, K. H. Severe head and neck injuries in NASS rear impacts. SAE paper 2008-010190, 2008.

9 Viano, D. C., Parenteau, C. S., Prasad, P., and Burnett, R. Occupant responses in high-speed rear crashes: analysis of government-sponsored tests. SAE paper 2008-01-0188, 2008.

10 Viano, D. C. and Parenteau, C. S. Serious injury in very-low and very-high speed rear impacts. SAE paper 2008-01-1485, 2008.

11 Krafft, M., Kullgren, A., Ydenius, A., and Tingvall, C. Influence of crash pulse characteristics on whiplash associated disorders in rear impacts crash recording in real life crashes. Traffic Injury Prevention, 2002, 3(2), 141-149.

12 Krafft, M., Kullgren, A., Malm, S., and Ydenius, A. Influence of crash severity on various whiplash injury symptoms: a study based on real-life rear- 
end crashes with recorded crash pulses. In Proceedings of the 19th International Technical Conference on Enhanced safety of vehicles, Washington DC, USA, 6-9 June 2005, paper 05-0363-O (National Highway Traffic Safety Administration, Washington, DC).

13 Himmetoglu, S., Acar, M., Bouazza-Marouf, K., and Taylor, A. J. A multi-body human model for rear-impact simulation. Proc. IMechE, Part D: J. Automobile Engineering, 2009, 223(5), 623-638. DOI: $10.1243 / 09544070 J A U T O 985$.

14 Himmetoglu, S., Acar, M., Taylor, A. J., and Bouazza-Marouf, K. A multi-body head-and-neck model for simulation of rear impact in cars. Proc. IMechE, Part D: J. Automobile Engineering, 2007, 221(5), 527-541. DOI: 10.1243/09544070JAUTO467.

15 Himmetoglu, S. Car seat design and human-body modelling for rear impact whiplash mitigation. PhD Thesis, Loughborough University, Loughborough, UK, 2008.

16 Kleinberger, M., Voo, L., Merkle, A., Szczepanowski, R., and McGee, B. A comparative study of dummy sensitivity to seat design parameters. In Proceedings of the 20th International Technical Conference on Enhanced safety of vehicles, Lyon, France, 18-21 June 2007, paper 07-0366.

17 Szabo, T. J., Voss, D. P., and Welcher, J. B. Influence of seat foam and geometrical properties on BioRID P3 kinematic response to rear impacts. Traffic Injury Prevention, 2003, 4(4), 315-323.

18 Lundell, B., Jakobsson, L., Alfredsson, B., Lindström, M., and Simonsson, L. The WHIPS seat - a car seat for improved protection against neck injuries in rear end impacts. In Proceedings of the 16th International Technical Conference on Enhanced safety of vehicles, Windsor, Canada, 31 May-4 June 1998, paper 98-S7-O-08 (National Highway Traffic Safety Administration, Washington, DC).

19 Jakobsson, L., Isaksson-Hellman, I., and Lindman, M. WHIPS (Volvo cars' whiplash protection system) - the development and real-world performance. Traffic Injury Prevention, 2008, 9(6), 600-605.

20 Viano, D. C. Role of the seat in rear crash safety, 2002 (Society of Automotive Engineers, Warrendale, Pennsylvania, USA).

21 Kullgren, A., Krafft, M., Lie, A., and Tingvall, C. The effect of whiplash protection systems in reallife crashes and their correlation to consumer crash test programmes. In Proceedings of the 20th International Technical Conference on Enhanced safety of vehicles, Lyon, France, 18-21 June 2007, paper 07-0468 (National Highway Traffic Safety Administration, Washington, DC).

22 Himmetoglu, S., Acar, M., Bouazza-Marouf, K., and Taylor, A. J. Energy-absorbing car seat designs for reducing whiplash. Traffic Injury Prevention, 2008, 9(6), 583-591.

23 van der Horst, M. J. Human head neck response in frontal, lateral and rear end impact loading: modelling and validation. $\mathrm{PhD}$ Thesis, Eindhoven University of Technology, Eindhoven, The Netherlands, 2002.

24 Cappon, H., Mordaka, J., Van Rooij, L., Adamec, J., Praxl, N., and Muggenthaler, H. A computational human model with stabilizing spine: a step towards active safety. SAE paper 2007-01-1171, 2007.

25 Bose, D. and Crandall, J. R. Influence of active muscle contribution on the injury response of restrained car occupants. In Proceedings of the 52nd Annual AAAM Scientific Conference, San Diego, California, 5-8 October 2008, pp. 61-72 (Association for the Advancement of Automotive Medicine, Barrington, Illinois, USA).

26 van Schijndel-de Nooij, M. and Wismans, J. APROSYS: Advances in secondary safety research. Int. J. Crashworthiness, 2008, 13(6), 591-598.

27 Davidsson, J., Ono, K., Inami, S., Svensson, M. Y., and Lövsund, P. A comparison between volunteer, BioRID P3 and Hybrid III performance in rear impacts. In Proceedings of the International IRCOBI Conference, Sitges, Spain, 23-24 September 1999, pp. 165-178 (International Research Council on Biomechanics of Injury, Zurich).

28 Wismans, J. Results of the EEVC whiplash dummy comparison programme. In Proceedings of the International Conference on Neck injuries in road traffic and prevention strategies, Munich, Germany, 5-6 November 2007, paper 22 (TÜV SÜD Akademie $\mathrm{GmbH}$, Munich).

29 Linder, A., Avery, M., Krafft, M., Kullgren, A., and Svensson, M. Y. Acceleration pulses and crash severity in low velocity rear impacts - real world data and barrier tests. In Proceedings of the 17th International Technical Conference on Enhanced safety of vehicles, Amsterdam, The Netherlands, 4-7 June 2001, paper 216 (National Highway Traffic Safety Administration, Washington, DC).

30 Linder, A., Avery, M., Krafft, M., and Kullgren, A. Change of velocity and crash pulse characteristics in rear impacts: real-world data and vehicle tests. In Proceedings of the 18th International Technical Conference on Enhanced safety of vehicles, Nagoya, Japan, 19-22 May 2003, paper 285 (National Highway Traffic Safety Administration, Washington, DC).

31 Verver, M. M. Numerical tools for comfort analyses of automotive seating. $\mathrm{PhD}$ Thesis, Eindhoven University of Technology, Eindhoven, The Netherlands, 2004.

32 Eriksson, L. Three-dimensional mathematical models of the BioRID I and car seats for low-speed rear-end impacts. Traffic Injury Prevention, 2002, 3(1), 75-87.

33 Krafft, M. A comparison of short and long term consequences of AIS 1 neck injuries in rear impacts. In Proceedings of the International IRCOBI Conference, Göteborg, Sweden, 16-18 September 1998, pp. 235-248 (International Research Council on Biomechanics of Injury, Zurich). 
34 Avery, M. and Weekes, A. M. Dynamic testing of vehicle seats to reduce whiplash injury risk: an international protocol. In Proceedings of the ICrash Conference, Athens, Greece, 4-7 July 2006, p. 11 (Taylor \& Francis Group).

35 International Insurance Whiplash Prevention Group (IIWPG). RCAR-IIWPG seat/head restraint evaluation protocol, Version 3, 2008 (Research Council for Automobile Repairs). Available from www.rcar.org.

36 Schmitt, K.-U., Muser, M. H., and Niederer, P. A new neck injury criterion candidate for rear-end collisions taking into account shear forces and bending moments. In Proceedings of the 17th International Technical Conference on Enhanced safety of vehicles, Amsterdam, The Netherlands, 4-7 June 2001, paper 124 (National Highway Traffic Safety Administration, Washington, DC).

37 Boström, O., Svensson, M. Y., Aldman, B., Hansson, H. A., Håland, Y., Lövsund, P., Seeman, T., Suneson, A., Säljö, A., and Örtengren, T. A new neck injury criterion candidate-based on injury findings in the cervical spinal ganglia after experimental neck extension trauma. In Proceedings of the International IRCOBI Conference, Dublin, Ireland, 11-13 September 1996, pp. 123-136 (International Research Council on Biomechanics of Injury, Zurich).

38 Krafft, M., Kullgren, A., Lie, A., and Tingvall, C. Assessment of whiplash protection in rear impacts crash tests and real-life crashes, 2004 (Swedish National Road Administration, Stockholm, Sweden).

39 Schmitt, K.-U. and Muser, M. Evaluating recent seat models in rear-end impacts according to currently discussed consumer test proposals. In Proceedings of the 21st International Technical Conference on Enhanced safety of vehicles, Stuttgart, Germany, 15-18 June 2009, paper 09-0116 (National Highway Traffic Safety Administration, Washington, DC).

40 Bortenschlager, K., Hartlieb, M., Barnsteiner, K., Ferdinand, L., Kramberger, D., Siems, S., Muser, M., and Schmitt, K.-U. Review of existing injury criteria and their tolerance limits for whiplash injuries with respect to testing experience and rating systems. In Proceedings of the 20th International Technical Conference on Enhanced safety of vehicles, Lyon, France, 18-21 June 2007, paper 07-0486.

41 Ikari, T., Kaito, K., Nakajima, T., Yamazaki, K., and Ono, K. Japan new car assessment program for minor neck injury protection in rear-end collisions. In Proceedings of the 21st International Technical Conference on Enhanced safety of vehicles, Stuttgart, Germany, 15-18 June 2009, paper 09-0364 (National Highway Traffic Safety Administration, Washington, DC).

42 Zellmer, H., Stamm, M., Seidenschwang, A., and Brunner, A. Enhancement of seat performance in low-speed rear impact. In Proceedings of the 17th
International Technical Conference on Enhanced safety of vehicles, Amsterdam, The Netherlands, 4-7 June 2001, paper 231 (National Highway Traffic Safety Administration, Washington, DC).

43 Schmitt, K.-U., Muser, M., Heggendorn, M., Niederer, P., and Walz, F. Seat component to prevent whiplash injury. In Proceedings of the 18th International Technical Conference on Enhanced safety of vehicles, Nagoya, Japan, 19-22 May 2003, paper 224 (National Highway Traffic Safety Administration, Washington, DC).

44 Hynd, D. and Willis, C. Recommendations for a low-speed rear impact sled test pulse, European Enhanced Vehicle-Safety Committee (EEVC) WG20 Report, Document No. 166, 2007. Available from www.eevc.org.

\section{Notation}

$\mathrm{a}_{\text {mean }}, \mathrm{a}_{\text {peak }}$ mean and peak accelerations respectively

AWD

BioRID

BioRID II anti-whiplash device

commercial version of BioRID

$\mathrm{Fsh}^{(-)}, \mathrm{Fsh}^{(+)}$negative and positive shear forces respectively acting on the head at the $\mathrm{OC}$

Ftn tension force acting on the head at the $\mathrm{OC}$

g gravitational acceleration

$\mathrm{HrCt}$ head restraint contact time

HR attached head-restraint model for all the seats

HS highest severity pulse

Hybrid III frontal crash test dummy

IFWMS reactive car seat concept with the inner frame

IIWPG International Insurance Whiplash Prevention Group

JARI Japan Automobile Research Institute

LRM locked recliner mechanism in TYPS seats

$\mathrm{N}_{\mathrm{km}} \quad$ neck injury criterion by Schmitt et al. [36]

NIC neck injury criterion by Boström et al. [37]

OC occipital condyles or upper neck

OF outer seat-back frame in IFWMS

$\mathrm{P} \quad$ translational AWD

P* translational spring-and-damper unit of the foam-plate 


\begin{tabular}{|c|c|c|c|}
\hline $\mathrm{R}$ & rotational AWD at the recliner & TYPS-G2 & typical car seat model - version G2 \\
\hline $\mathrm{R}^{*}$ & rotational AWD in IFWMS, & $\mathrm{V}_{\mathrm{r}}$ & head rebound velocity \\
\hline & connecting $\mathrm{OF}$ to $\mathrm{SB}$ & WHIPS & whiplash protection system \\
\hline RID-neck & dummy neck used as part of Hybrid & WMS & reactive car seat concept \\
\hline & III in rear-impact tests & WMS-SO & WMS with the softer recliner \\
\hline $\mathrm{S}_{\mathrm{G}}$ & inertial coordinate system & WMS-ST & WMS with the stronger recliner \\
\hline SAHR & Saab active head restraint & & \\
\hline SB & seat-back with which the torso & & \\
\hline & directly interacts & $\Delta_{\mathrm{P} *}$ & foam-plate displacement at $\mathrm{P}^{*}$ \\
\hline $\mathrm{SN}$ & sinusoidal type pulse & $\Delta \mathrm{V}$ & change in the velocity of a vehicle \\
\hline SNRA & Swedish National Road & & subjected to a crash pulse \\
\hline SP & $\begin{array}{l}\text { Administration } \\
\text { seat-pan }\end{array}$ & $\Delta x_{\text {LRM }}$ & $\begin{array}{l}\text { horizontal translation of the SB } \\
\text { relative to the SP in TYPS seats }\end{array}$ \\
\hline $\mathrm{T} 1$ & first thoracic vertebra & $\Delta x_{\mathrm{SP}}$ & seat-pan displacement at $\mathrm{P}$ \\
\hline $\begin{array}{l}\mathrm{T} 1_{\mathrm{x}-\mathrm{acc}} \\
\mathrm{TR}\end{array}$ & $\begin{array}{l}\mathrm{T} 1 \text { forward acceleration } \\
\text { tranezoidal type pulse }\end{array}$ & $\Delta \theta_{\mathrm{LRM}}$ & rotation of the SB relative to the SP in \\
\hline TYPS & typical car seat model & & TYPS seats \\
\hline TYPS-B1 & typical car seat model - version B1 & $\Delta \theta_{\mathrm{R} *}$ & $\begin{array}{l}\text { rotation at } \mathrm{R}^{*} \\
\text { total change in seat-back }(\mathrm{SB}) \text { angle }\end{array}$ \\
\hline
\end{tabular}

